\title{
Studies Regarding the Nickel Electrodeposition from Choline Chloride Based Ionic Liquids
}

\author{
Liana Anicai ${ }^{1}$, Andreea Florea ${ }^{1}$ and Teodor Visan ${ }^{2}$ \\ ${ }^{1}$ Direction of Research, PSV Company SA, Bucharest \\ 2Department of Physical Chemistry and Applied Electrochemistry, University \\ POLITEHNICA of Bucharest, \\ Romania
}

\section{Introduction}

The electrochemical technologies are extensively applied in a large range of industrial fields, from decorative/protective coatings in electrical engineering, electronics, automotive or machine building domains towards the manufacturing of microelectronic components, of micro-electro-mechanical systems (the so-called MEMS) or of the high precision micro- and nanostructures, including biological ones (Data \& Landolt, 2000; Gurunathan et al., 1999). Due to the fact that electrochemical deposition is an atomic/molecular level process, the formed layer entirely takes the three-dimensional shape of the substrate with a very high accuracy.

As a result of the last years scientific progress, the theoretical aspects of electrochemical engineering principles applicable for electrochemical micro-processing have significantly developed so that, associated with performance techniques and equipment lead to the new and innovative materials development having controlled micro- or nanostructures.

In spite of a long history and experience, the metals surface finishing industry still has not been successful in extending the range of the metals able to be electrodeposited towards some of them with a promising technical potential, such as Al, W, Mo, Ti. Their capability to form stable oxides represents an obstacle against their application as coating layers, especially from classical aqueous electrolytes.

Moreover, in the last decade sustained efforts have been made to preserve the environment and to minimize the toxic effects of certain electrochemical technologies on human health. Thus, certain metallic coatings have been and still are subjected to some use restrictions such as $\mathrm{Cr}, \mathrm{Ni}$, but $\mathrm{Cu}, \mathrm{Ag}$ and $\mathrm{Au}$ as well, due to the involvement of aqueous cyanide electrolytes.

Taking into account the above mentioned considerations, in the last 10 years investigations to develop and promote alternative more environmentally friendly electrochemical media have been reported, including the class of the so-called "ionic liquids", defined as "ionic materials in liquid state for temperatures lower than ${ }^{100}{ }^{\circ} C^{\prime \prime}$ (Endres et al., 2008; Wasserscheid \& Welton, 2007).

The ionic liquids have some properties which make them adequate as metal electrodeposition electrolytes, such as: 
- $\quad$ wide potential window;

- $\quad$ high solubility of metallic salts;

- minimization/absence of secondary reactions due to the water presence;

- $\quad$ higher conductivity as compared with non-aqueous/organic solvents.

These types of ionic media thus may offer the possibility to obtain metallic coatings that are hard or impossible to be obtained in classical aqueous solutions or to apply these coating layers with a suitable adherence on water sensitive metallic substrates such as $\mathrm{Al}, \mathrm{Mg}, \mathrm{Ti}$ and their alloys, stainless steels, other alloys containing high contents of refractory or rare earth metals (Endres et al., 2008; Endres, 2002; Mukhopadhyay et al., 2005).

Recently it has been shown the possibility of formation of ionic liquids from eutectic mixtures of quaternary ammonium salt such as choline chloride (2-hydroxy-ethyl-trimethyl ammonium chloride) with a hydrogen bond donor species such as amides, glycols or carboxylic acids ( Abbott et al., 2003; Endres, 2002; Endres et al., 2008; Mukhopadhyay et al., 2005; Wasserscheid \& Welton, 2007). These media, also known as "deep eutectic solvents", have been further used to electrodeposit a large range of metals and alloys including $\mathrm{Zn}$ and Zn alloys, Cr, Sn and Sn alloys, Cu and Ag ( Abbott et al., 2003; Abbott et al., 2006; Abbott et al., 2007; Cojocaru et al., 2009; Endres et al., 2008; Florea et al., 2010).

Having in mind all of the above, the chapter will present some general information regarding the preparation and characterization of choline chloride based ionic liquids, as well as their use as plating electrolytes. Afterwards, several experimental results obtained by our group are discussed, regarding the electrochemical Ni deposition which allowed us to get more consistent information on the technological parameters influence during plating onto various metallic substrates (e.g. $\mathrm{Cu}, \mathrm{Al}, \mathrm{Mg}$ ). $\mathrm{NiCl}_{2}$ and for the first time $\mathrm{NiSO}_{4}$ have been involved as precursors for the metallic cations.

\section{General aspects regarding the synthesis and characterization of choline chloride based ionic liquids}

An ionic medium with interesting perspectives in metals electrodeposition is that based on choline chloride (2-hydroxy-ethyl-trimethyl ammonium chloride) mixed with urea. They proved to be very attractive in the field of metal and alloy electrodeposition. The ionic liquid is formed due to the hydrogen bonds formed between the ammonium quaternary salt and amide.

These new ionic media are potentially recyclable, biodegradable and with no proven adverse effects on human health. Thus they show good potential for a "green alternative" for metal and alloy electrodeposition as well as for other various chemical processes. Currently, the interest is focused towards those kinds of ionic liquids formed by the mixture of choline chloride with a metal salt, alcohol, amide or organic acid (Abbott et al., 2001; Abbott et al., 2003; Abbott et al., 2003; Abbott et al., 2004; Abbott et al., 2006; Endres 2002). This electrochemical medium is also characterized by good air and water stability with no additional precautions.

Abbott et al.(Abbott et al., 2004) have investigated in detail the possibility of formation of various ionic liquids based on choline chloride which usually are characterized by a freezing point of up to $100{ }^{\circ} \mathrm{C}$, but more usual around $60^{\circ} \mathrm{C}$, through the reaction between a quaternary ammonium salt (compound $\mathrm{A}$ ) having the general formula:

$\mathrm{R}^{1} \mathrm{R}^{2} \mathrm{R}^{3} \mathrm{R}^{4} \mathrm{~N}^{+} \mathrm{X}^{-}$ 
and an organic compound $\mathrm{B}$ which is in a solid form at $20^{\circ} \mathrm{C}$ and is able to form hydrogen bonds with $\mathrm{X}$ -

$\mathrm{R}^{1}, \mathrm{R}^{2}, \mathrm{R}^{3}$ and $\mathrm{R}^{4}$ can be:

- $\mathrm{H}$,

- $\quad$ a $C_{1}$ to $C_{5}$ alkyl group or

- $\quad$ a $C_{6}$ to $C_{10}$ cycloalkyl group or alkylene group or

- a $\mathrm{C}_{6}$ to $\mathrm{C}_{12}$ alkyl or cycloalkyl group, substituted with various functional groups such as: $\mathrm{OH}^{-}, \mathrm{Cl}, \mathrm{Br}, \mathrm{F}, \mathrm{I}, \mathrm{NH}_{2}$, etc.

$\mathrm{X}$ - represents a suitable counter ion.

The organic compound B may usually be urea, aniline, hydroxyaliphatic acids, dicarboxylic acids, phenol, ethylene glycol or citric acid.

$\mathrm{A}$ and $\mathrm{B}$ compounds are mixed in molar ratios between 1:1.5 up to 1:2.5. Generally, the preferred quaternary ammonium salts are those exhibiting asymmetry and $R 1, R^{2}, R^{3}$ and $R^{4}$ are recommended not to be identical.

Choline chloride mixtures with various types of B compounds may be considered as eutectic ones, having the melting point much lower as compared with that of the individual components (Abbott et al., 2004).

Choline chloride - carboxylic acids eutectic mixtures are easy to prepare, they don't react with water and are usually biodegradable. The components toxicological characteristics are already well known. These mixtures have led to the identification of a new class of solvents whose physical properties are similar to the "traditional" ionic liquids and are correlated with the number of functional groups, of alkyl/aryl substituents and with the mixture composition. These "eutectic solvents" dissolve various metallic oxides so that they may be considered as potential suitable media for the metal extraction (Abbott et al., 2004; Abbott et al., 2004).

The deep eutectic solvents based ionic liquids may be thus described by the general formula:

$$
\mathrm{R}_{1} \mathrm{R}_{2} \mathrm{R}_{3} \mathrm{R}_{4} \mathrm{~N}^{+} \mathrm{X} . \mathrm{YY}
$$

and they have been characterized into three types depending on the complexing agent, $\mathrm{Y}$ :

Type I $\mathrm{Y}=\mathrm{MCl}_{\mathrm{x}}, \mathrm{M}=\mathrm{Zn}, \mathrm{Sn}, \mathrm{Fe}, \mathrm{Al}, \mathrm{Ge}$

TypeII $\mathrm{Y}=\mathrm{MCl}_{\mathrm{x}} \mathrm{yH}_{2} \mathrm{O}, \mathrm{M}=\mathrm{Cr}, \mathrm{Cu}, \mathrm{Co}, \mathrm{Ni}, \mathrm{Fe}$

Type III $\mathrm{Y}=\mathrm{RZ}, \mathrm{Z}=\mathrm{CONH}_{2}, \mathrm{COOH}, \mathrm{OH}$

$\mathrm{X}$ is usually a halide anion (mostly $\mathrm{Cl}$ ). ( Abbott et al., 2001; Abbott et al., 2004; Abbott \& McKenzie, 2006).

In the case of Type I and II eutectics the potential window is limited at high potentials by chlorine gas evolution and at low potentials by the metal ion reduction with metal deposition from the melt. Type I eutectics have been prepared using $\mathrm{Zn}, \mathrm{Sn}, \mathrm{Fe}, \mathrm{Al}, \mathrm{Ge}$ and $\mathrm{Cu}$ chlorides. Their reduction potential is shifted towards more electronegative values as the metal halide is closer by Lewis acid. Because the reduction potential is associated with Lewis acidity, the corresponding proportions of metal and quaternary ammonium salts affect the potential window. Type II eutectics have been developed in order to extend the range of metals able to be electrodeposited from ionic liquids and $\mathrm{Cr}$ electrodeposition with good characteristics has been reported (Abbott et al., 2004; Abbott et al., 2004; Benaben \& Sottil, 2006). Hydration water plays a significant role on the stability and fluidity of choline chloride based ionic liquids. In this case water behaviour is different compared to the case of aqueous electrolytes and the potential window is limited rather by the metallic species 
reduction than the water-related reduction processes. The metal can be reduced with a high cathodic efficiency and the reaction is not affected by a max. $10 \%$ water content; this phenomenon suggests the water is associated either with chloride anions or with the central metal.

The eutectic based ionic liquids are considerably less sensitive to water addition and sometimes its presence has a positive effect on the deposit morphology.

In the case of ionic liquids containing high amounts of halides, the chemical attack of the metallic oxides at the electrode surface occurs; that means that only few metals are really inert in these media and consequently the anodic potential limit is governed rather by the metal oxidation. Even metals such as $\mathrm{Pt}, \mathrm{Au}, \mathrm{Al}$ and $\mathrm{Ti}$ may be oxidized in ionic liquids and their oxides can be dissolved especially in eutectics containing chloride ions as ligands for metallic ions dissolution. This phenomenon allows the use of soluble anodes during electrodeposition procedure.

The process of metals electrodissolution in ionic liquids has been applied to develop several electropolishing procedures suitable for stainless steel, when a Type III eutectic has been involved containing ethylene glycol as the hydrogen bond donor (Abbott et al., 2004; Abbott et al., 2006) The anodic dissolution occurs in the same manner as in the case of the aqueous phosphoric and sulphuric acids electrolytes but the current efficiency was significantly improved up to about $90 \%$ and the ionic medium is much less toxic and corrosive.

Abbott et al (Abbott et al., 2004; Abbott et al., 2004; Abbott et al., 2004; Benaben \& Sottil, 2006) have reported several investigations regarding the formation of choline chloride based ionic liquids with various kinds of hydrated metallic salts, potentially able to be applied for electrodeposition and electropolishing. The involved metallic compounds have chlorides or nitrates as anions and the freezing point is up to $50^{\circ} \mathrm{C}$. When other types of metallic salts have been employed, such as acetates, sulphates, the resulted ionic compound doesn't become solid at temperatures over $50^{\circ} \mathrm{C}$ but the liquid state is maintained on a narrower domain.

The use of ionic liquids to perform various metal surface treatments allows the replacement of several toxic chemical reagents such as $\mathrm{CrO}_{3}$ in the case of chromium plating from aqueous electrolytes and $\mathrm{KCN}$ involved in $\mathrm{Ag}$, $\mathrm{Cu}$ and $\mathrm{Zn}$ electrodeposition.

When ionic liquid systems are intended to be applied for electrodeposition their behaviour has to be assessed as compared with the case of aqueous electrolytes. The main factors which affect the overall electrochemical process include viscosity, conductivity, the potential window, the ionic medium chemistry as well as the structure of the electrical double layer and redox potentials. All these parameters will influence the diffusion rate of metallic ions at the electrode surface as well as the thermodynamics and kinetics of the reduction process. Consequently, the nucleation/growth mechanisms and the deposit morphology will be affected, too. More detailed discussions on this topic may be found in ( Abbott et al., 2004; Abbott et al., 2004; Abbott \& McKenzie, 2006; Abbott et al., 2007; Endres et al., 2008 and included references).

\section{Metal and alloy electrodeposition from choline chloride based ionic liquids}

The electrodeposition of metals and alloys in this type of ionic liquid appeared attractive because they are air and moisture stable. Moreover, some of these systems are very good candidates as replacement technologies for aqueous processes that often require strong inorganic acids or toxic co-ligands. Abbott and his group had a significant contribution on 
this topic through reporting a large range of experimental results regarding metal and alloy plating including $\mathrm{Zn}$ and $\mathrm{Zn}$ alloys, $\mathrm{Cr}$, Sn and $\mathrm{Sn}$ alloys, $\mathrm{Cu}$ and $\mathrm{Ag}$ (Abbott et al., 2004; Abbott et al., 2007; Abbott et al., 2007; Abbott et al., 2008; Abbott et al., 2009; Abbott et al., 2009; Benaben \& Sottil, 2006).

$\mathrm{Zn}$ and $\mathrm{Zn}$ alloys electrodeposition has attracted a great interest due to their large applications as anticorrosive layers in a wide range of industrial fields. Moreover, they represent an environmentally friendly alternative to $\mathrm{Cd}$ depositions as well. Regarding the electrodeposition process, Abbott et al. (Abbott et al., 2009) found that nucleation in the urea based liquid is fast but bulk growth is slow, whereas nucleation in the glycol based liquid is slow but bulk growth is relatively fast. Critical surface coverage necessary for the transition from nucleation to bulk growth is similar for both liquids. Whitehead et al.(Whitehead et al., 2010) have investigated the zinc deposition process from a basic choline chloride/ethylene glycol deep eutectic solvent containing $\mathrm{ZnCl}_{2}$ at $30^{\circ} \mathrm{C}$. On sweeping or stepping the potential to -0.5 to $-0.8 \mathrm{~V}$ vs. $\mathrm{Zn} / \mathrm{Zn}$ (II), only little deposition takes place initially, with a more rapid deposition being observed when the potential was subsequently raised to -0.4 to $-0.2 \mathrm{~V}$. The role of choline chloride was also studied by comparing with a choline-free electrolyte, which exhibited a more conventional voltammetric response. The formation of a dissolved, intermediate species $Z$ on the cathodic sweep was proposed to account for the observed deposition behavior in the deep eutectic. Furthermore, an observation of the electrodeposition behavior with the addition of sodium ethoxide supported the suggestion that $\mathrm{Z}$ is a complex of $\mathrm{Zn}^{2+}$ and deprotonated components of the solvent. To improve the appearance of $Z n$ coatings from ionic liquids, several brighteners have been investigated, such as acetonitrile, ethylene diamine and ammonia (Abbott et al. 2010). Ammonia was initially chosen as previous studies have determined that $\mathrm{Zn}$ is effectively complexed by this ligand in aqueous sulphate electrolytes. Acetonitrile and ethylene diamine were chosen to represent a weaker and a stronger nitrogen containing ligand respectively. Ammonia and ethylene diamine have shown to be effective brighteners for $\mathrm{Zn}$ deposition. EXAFS investigation proved however that this was not because of the $\mathrm{Zn}$ ions complexation but rather due to the different hydrogen bond strengths of the additives.

Some experimental investigations dealing with $\mathrm{Cr}$ electrodeposition from choline chloride based ionic liquids have been reported in (Abbott et al., 2004; Abbott et al., 2004; Abbott et al., 2004; Benaben \& Sottil, 2006), involving a Type II eutectic with $\mathrm{CrCl}_{3} \cdot 6 \mathrm{H}_{2} \mathrm{O}$. The obtained results have shown that thick, adherent, crack free deposits of chromium black can be electrodeposited from an ionic liquid containing $\mathrm{Cr}$ (III). The morphology of the deposits can be made nanocrystalline by the incorporation of $\mathrm{LiCl}$ into the ionic liquid. The chromium containing species present in the liquid change following the addition of $\mathrm{LiCl}$ and the species $\left[\mathrm{Cr}\left(\mathrm{H}_{2} \mathrm{O}\right)_{2} \mathrm{Cl}_{4}\right]$-has been identified for the first time. The chromium films showed corrosion resistance following a post-treatment electrolysis in aqueous potassium nitrate solutions.

Tin and tin alloys with Zn (Abbott et al., 2007) or Ni (Cojocaru et al., 2009; Cojocaru et al., 2009) have been also electrodeposited from deep eutectic solvents. It has been found that the nature of hydrogen bond donor significantly influences the ionic liquid electrochemistry and the morphology of the deposit. In the case of $\mathrm{ZnSn}$ alloy the morphology and composition can be changed by judicious choice of the ionic liquid. It was proposed that metal speciation is a cause of metal reduction thermodynamics.

Ni-Sn alloy morphology was also found to be dependent on the ionic liquid composition and on operating parameters, but the chemical composition was found to be quite constant, regardless the value of the applied current density (Florea et al., 2010). 
Abbott et. Al ( Abbott et al., 2009) described the electrolytic deposition of copper and copper composites from a solution of the metal chloride salt in either urea-choline chloride, or ethylene glycol-choline chloride based eutectics. It has been found that the deposition kinetics and thermodynamics are quite unlike those in aqueous solution under comparable conditions and that the copper ion complexation is also different. The mechanism of copper nucleation was investigated using chronoamperometry and it was shown that progressive nucleation leads to a bright nano-structured deposit. In contrast, instantaneous nucleation, at lower concentrations of copper ions, leads to a dull deposit. The electrochemical quartz crystal microbalance (EQCM) has been involved to monitor both current efficiency and the inclusion of inert particulates into the copper coatings. It was found that the composition of composite material was strongly dependent on the amount of species suspended in solution. The majority of material was dragged onto the surface rather than settling on to it. The distribution of the composite material was found to be even throughout the coating. This technology may be important because it facilitates deposition of bright copper coatings without co-ligands such as cyanide.

Abbott et al ( Abbott et al., 2007; Abbott et al. 2008) have reported for the first time the electroless Ag deposition onto $\mathrm{Cu}$ substrates from Ag ions containing choline chloride ethylene glycol ionic liquids, which represents a technological procedure with a reduced impact on environment. The authors have shown that Ag deposition on $\mathrm{Cu}$ takes place due to the thermodynamic reduction of $\mathrm{Ag}^{+}$and to the $\mathrm{Cu}^{+}$dissolution which are determined by the redox potential difference of the two involved metallic ions. In these eutectic mixtures, the hydrogen bond donor species is ethylene glycol. The obtained experimental results have supported a deposition mechanism involving a rapid nucleation followed by a slower growth step that suggests a limitation due to the mass transport. The Ag layer adherence is adequate to prevent $\mathrm{Cu}$ substrate corrosion and welding procedures on printed circuit tracks have been successfully tested. Florea et al. (Florea et al., 2010) showed some preliminary results regarding electrochemical Ag plating involving choline chloride and triethanolamine based ionic liquids which allowed successful deposition of Ag layers of a good quality and adherence to the $\mathrm{Cu}$ substrate. Based on XRD measurements, the average size of crystallites was about 28-35 nm for pure Ag deposits.

Abbott et al. (Abbott et al., 2008) have reported several preliminary investigations regarding $\mathrm{Ni}$ coatings from nickel chloride dissolved separately in either a urea or ethylene glycol/choline chloride based ionic liquid. From cyclic voltammograms the shape of the stripping peaks depended upon sweep rates, illustrating that the process is kinetically slow. The morphology and composition can be changed by the judicious choice of IL and the addition of complexing agents such as ethylenediamine and acetylacetonate as brighteners. Both additives suppress UPD of Ni and lead to smaller particulate deposits.

More detailed investigations performed by our group dealing both with the synthesis and characterization of the formed nickel salts (chloride and for the first time sulphate) containing ionic liquids and the electrochemical $\mathrm{Ni}$ deposition onto various metallic substrates to get more consistent information on the technological parameters, will be presented in the next sections.

\section{Nickel electrodeposition from choline chloride based ionic liquids}

\subsection{Synthesis and characterization of ionic liquids systems containing nickel salts}

Various ionic liquids based on choline chloride (noted as $\mathrm{ChCl}$ ) - urea (symbolized IL) and choline chloride - ethylene glycol (symbolized ILEG) (1:2 molar ratio) eutectics have been synthesized involving various $\mathrm{Ni}$ salts, respectively $\mathrm{NiCl}_{2} \cdot 6 \mathrm{H}_{2} \mathrm{O}$ and $\mathrm{NiSO}_{4} .7 \mathrm{H}_{2} \mathrm{O}$ with 
concentrations between $0-1.68 \mathrm{M}$. They have been further characterized with regard to the preparation conditions, appearance, fluidity against applied temperature, time stability. All chemical reagents have been of analytical grade. Choline chloride (Aldrich) has been used as received. The dependence of electrical conductivity against the temperature has been determined for several systems, using a WTW (Germany) 340i model conductometer with the cell constant $\mathrm{K}=0,469 \mathrm{~cm}^{-1}$.

In the case of IL - $\mathrm{NiCl}_{2}$ containing mixtures, all of them have been liquids at room temperature $\left(25^{\circ} \mathrm{C}\right)$ and the freezing point attained $5^{\circ} \mathrm{C}$. Their color varied from green to dark green depending on the Ni (II) salt content, as it can be also seen in Figure 1.

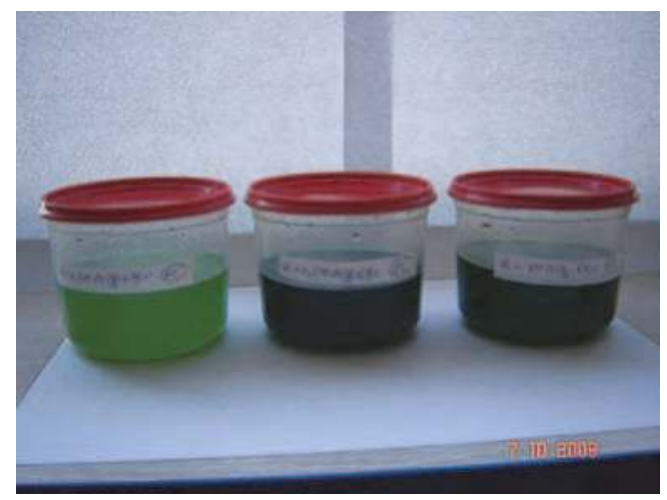

Fig. 1. Ionic liquids containing $\mathrm{NiCl}_{2}$ in various concentrations

Usually, the electrical conductivity takes values between $1-14 \mathrm{mS} / \mathrm{cm}$ for a temperature interval between $25-80^{\circ} \mathrm{C}$. Slightly higher values are evidenced in the case of $\mathrm{NiCl}_{2}$ low content in the mixture, as it can be also noticed in Figure.2. At a $0.5 \mathrm{M} \mathrm{Ni}$ (II) the conductivity exhibited a minimum. This behaviour might be due to the possible formation of several metallic complexes, $\mathrm{M}^{\mathrm{x}} \mathrm{Cl}_{\mathrm{x}+1}$, through the dissolution of $\mathrm{M}^{\mathrm{x}} \mathrm{Cl}_{\mathrm{x}}$ metallic halide in this eutectic solvent, whose speciation has not yet explained (Abbott et al., 2008).

The conductivity of ionic liquids $\sigma$ varies with temperature according to equation (3):

$$
\ln \sigma=\ln \sigma_{o}-\frac{E_{\Lambda}}{R \cdot T}
$$

where $E_{\Lambda}$ is the activation energy for conduction, $T$ is the absolute temperature and $\sigma_{o}$ is a constant. Consequently, from semi logarithmic Arrhenius type plots (Abbott et al., 2004; Florea, 2010) activation energies between $25-28 \mathrm{~kJ} / \mathrm{mol}$ have been determined ( $\mathrm{r}>0.988)$, which are slightly higher as compared to those of high temperature molten salts.

For the above presented systems, viscosities $(\eta)$ in the range of 30-700 cP have been measured for temperatures between $25^{\circ} \mathrm{C}-70^{\circ} \mathrm{C}$. These values are significantly lower as compared with other choline chloride-metallic salts systems, respectively $\mathrm{ChCl}-\mathrm{CrCl}_{3} \cdot 6 \mathrm{H}_{2} \mathrm{O}$ (Abbott et al., 2004) or $\mathrm{ChCl}-\mathrm{ZnCl}_{2}$ (Abbott et al., 2004). In the case of ionic fluids, the conductivity is usually governed by the charge carriers mobility. Consequently, the $\sigma-1 / \eta$ representations should be approximately linear for a certain charge carrier. This situation might be more complex in the case of ionic liquids containing metallic halides (in our case $\mathrm{NiCl}_{2}$ ) due to the possibility of various complex compounds formation. Figure 3 shows this 


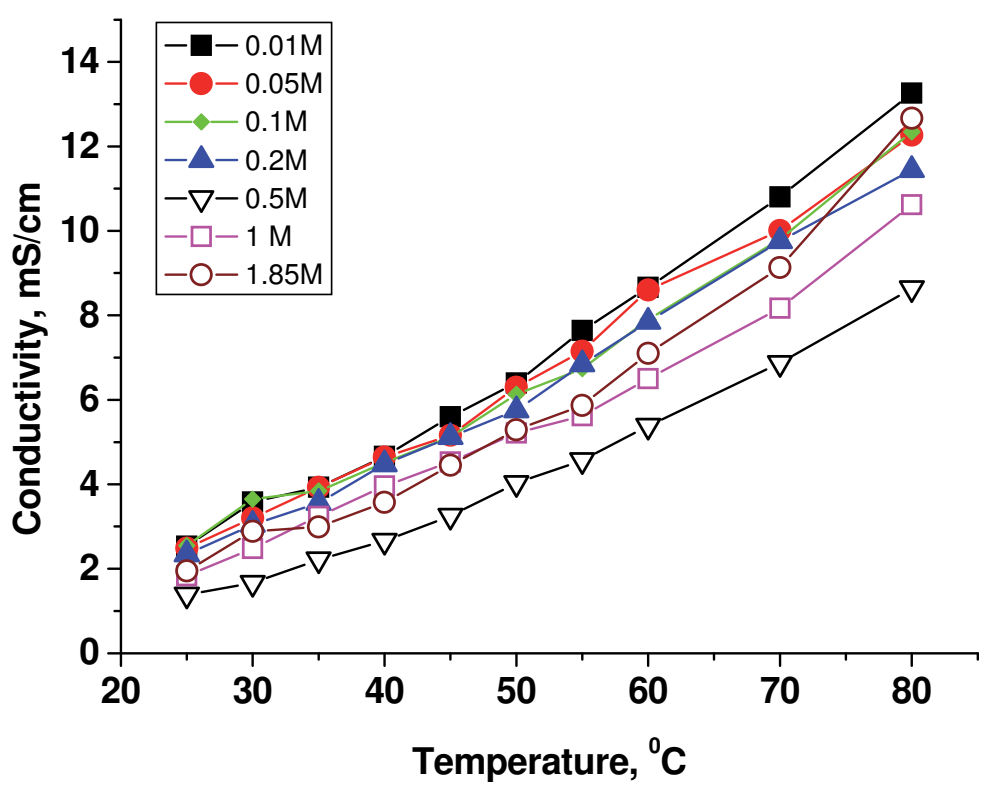

Fig. 2. Dependence of conductivity vs. temperature for IL systems containing various nickel chloride concentrations.

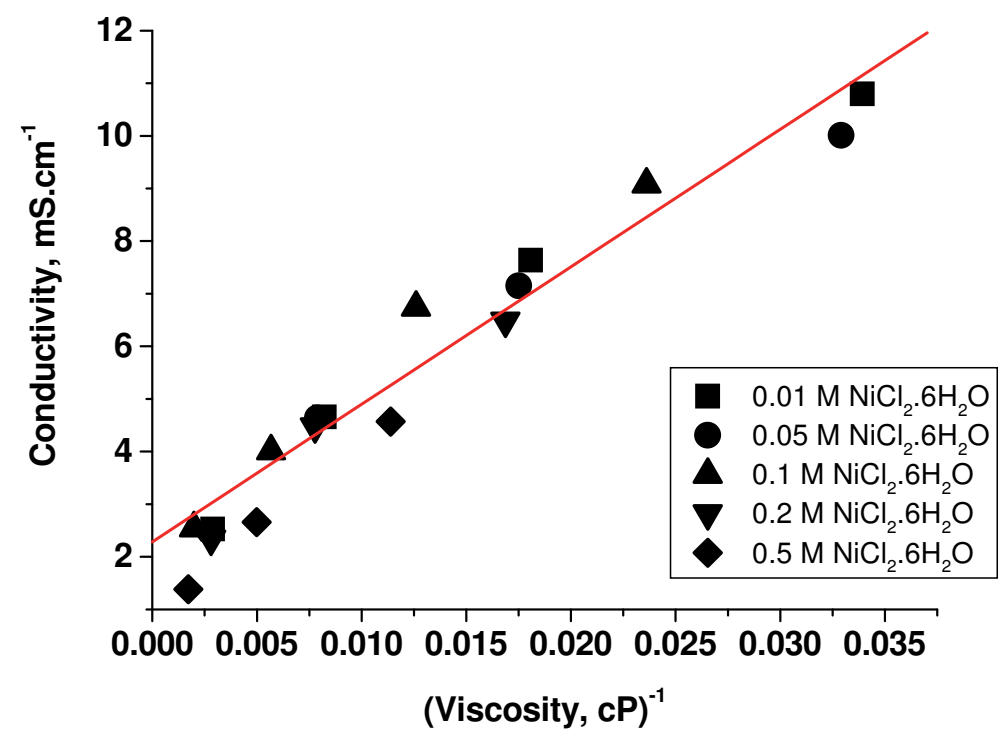

Fig. 3. Conductivity as a function of fluidity for different $\mathrm{ChCl}$-urea- $\mathrm{NiCl}_{2} \cdot 6 \mathrm{H}_{2} \mathrm{O}$ systems. 
dependence for several concentrations of the dissolved metallic salt in the ChCl-urea eutectic mixture. It can be evidenced that the ionic mobility is controlled by the ionic liquid conductivity and the slope is almost constant for all analyzed compositions, thus suggesting the presence of a single charge carrier species. These results are in agreement with other literature data (Abbott et al., 2004; Abbott et al., 2004).

The possibility of the synthesis of choline chloride based systems but where the metallic cation source was $\mathrm{NiSO}_{4}$ was also investigated, since according to the environmental legislation and to REACH requirements (Registration, Evaluation and Authorisation of Chemicals - the REACH system), there are discussions dealing with the restricted use of $\mathrm{NiCl}_{2}$ due to its potential risk on human health.

In the case of ionic liquids based on $\mathrm{Ni}$ (II) sulfate, the maximum salt concentration allowing a liquid state was found to be $1 \mathrm{M}$, higher values leading to the formation of a solid mixture. Typically, the electrical conductivity is situated in the range of $1-12 \mathrm{mS} / \mathrm{cm}$ for a temperature domain between $20-80^{\circ}$ C.Slightly higher values were measured for lower $\mathrm{Ni}$ (II) concentrations. Figure 4 presents examples of the semi logarithmic Arrhenius type plots in the case of $\mathrm{ChCl}$-urea-NiSO $4.7 \mathrm{H}_{2} \mathrm{O}$ systems. The determined values of activation energies $\left(E_{\Lambda}\right)$ as shown in Table 1, are relatively larger than those characteristic to high temperature molten salts.

The same investigations were performed but using ILEG as solvent. According to the experimental results (not shown here), green, stable liquids at room temperature $\left(25^{\circ} \mathrm{C}\right)$ were obtained regardless of the anion of the Ni salt, having conductivities in the range of 2 $22 \mathrm{mS} / \mathrm{cm}$ for a temperature range between $20-80^{\circ} \mathrm{C}$.

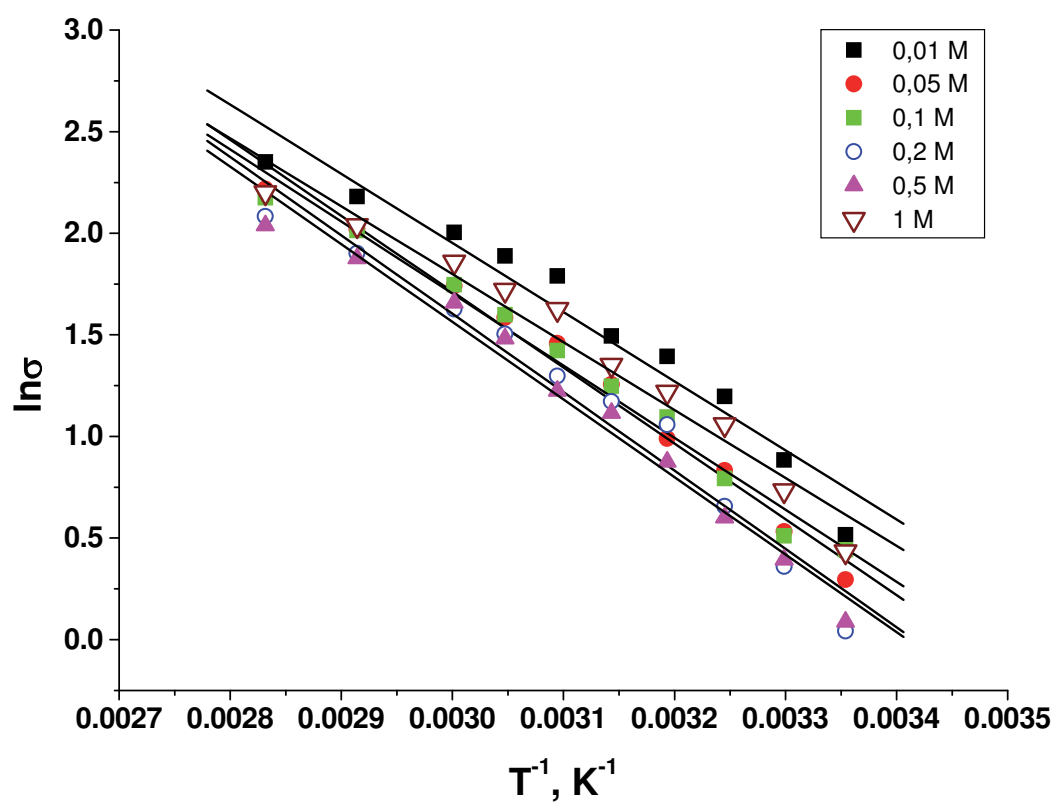

Fig. 4. Plots of log conductivity vs. reciprocal of temperature for IL systems containing various nickel sulfate concentrations. 


\begin{tabular}{|c|c|c|}
\hline $\begin{array}{c}\text { Molar concentration of } \\
\mathrm{NiSO}_{4} .7 \mathrm{H}_{2} \mathrm{O} \text { in ChCl:urea IL as solvent, } \\
\text { Mol/L }\end{array}$ & $\begin{array}{c}\mathrm{E}_{\Lambda,} \\
\mathrm{kJ} / \mathrm{mol}\end{array}$ & $\mathrm{r}$ \\
\hline 0.01 & 28.3 & 0.975 \\
\hline 0.05 & 31.04 & 0.993 \\
\hline 0.1 & 29.5 & 0.991 \\
\hline 0.2 & 32.07 & 0.981 \\
\hline 0.5 & 31.75 & 0.989 \\
\hline 1 & 27.8 & 0.981 \\
\hline
\end{tabular}

Table 1. Activation energies for conductivity $\left(\mathrm{E}_{\Lambda}\right)$ against ionic liquid composition (Coefficients of correlation ( $\mathrm{r}$ ) are also given).

The activation energies were found to be between $11-22 \mathrm{~kJ} / \mathrm{mol}$ for ILEG- $\mathrm{NiCl}_{2}$ systems and between $12-24 \mathrm{~kJ} / \mathrm{mol}$ for ILEG-NiSO 4 ones. It should be noted that the use of $\mathrm{ChCl}-$ ethylene glycol eutectic as solvent led to slightly lower values of activation energy as compared with the case of $\mathrm{ChCl}$-urea mixture, probably due to a relatively different speciation (Abbott et al., 2008).

\subsection{Electrochemical characterization of processes in $\mathrm{Ni}(\mathrm{II})$ compounds based ionic liquids through cyclic voltammetry}

To obtain more information on the electrochemical processes occurring in choline chloride based systems containing various amounts of nickel salts (chloride and sulfate), cyclic voltammetry experiments have been performed using an Autolab PGSTAT 12 potentiostat controlled with GPES software. A three electrode system consisting of a Pt working electrode with a constant geometrical surface of $0.19625 \mathrm{~cm}^{2}$, a graphite counter electrode and a silver wire quasi-reference electrode was used. The working electrode surface has been mechanically prepared using 1200 abrasive paper, rinsed and dried before each measurement. All voltammograms have been recorded in stationary conditions, at a potential sweep rate of $10 \mathrm{mV} / \mathrm{s}$. The $\mathrm{Ni}^{2+}$ concentration has been in the range of $0-1.85 \mathrm{M}$ for metallic chlorides and of 0-1M for sulfates.

Several examples of the recorded voltammograms at different applied working temperatures are presented in Figures 5, 6 and 7, for the case of choline chloride-urea based ionic liquids where the cation source has been provided as chloride.

As it can be seen from the figures, a quasi-reversible behaviour is evidenced on the investigated range of potential. The $\mathrm{Ni}^{2+}$ reduction process on the cathodic branch occurs at around $-0.81 \div-1.3 \mathrm{~V} / \mathrm{Ag}$ quasi-ref. at relatively low temperatures between $30-40{ }^{\circ} \mathrm{C}$, which shifts towards more electropositive values of $-0.55 \div-0.85 \mathrm{~V} / \mathrm{Ag}$ quasi-ref. as temperature increased to $80^{\circ} \mathrm{C}$.

Increasing the $\mathrm{Ni}^{2+}$ concentration from $0.01 \mathrm{M}$ to $1.85 \mathrm{M}$ shifts the cathodic potential towards more electronegative values especially at higher values of the applied temperature. When the metal content is higher than $0.2 \mathrm{M}$ and the working temperature is in the range of $40^{\circ} \mathrm{C}$ $60^{\circ} \mathrm{C}$ a small cathodic limiting current plateau is evidenced of about $2.5-9.8 \mathrm{~mA} / \mathrm{cm}^{2}$, higher as the metal content and temperature increased. It should be noted that the reduction process in this case is not so well defined compared to the electrochemical behaviour of other metals in the same ionic medium, such as $\mathrm{Cu}$ and Ag (Abbott et al., 2005; Abbott et al., 2008; Abbott et al., 2009; Anicai et al., 2008). 


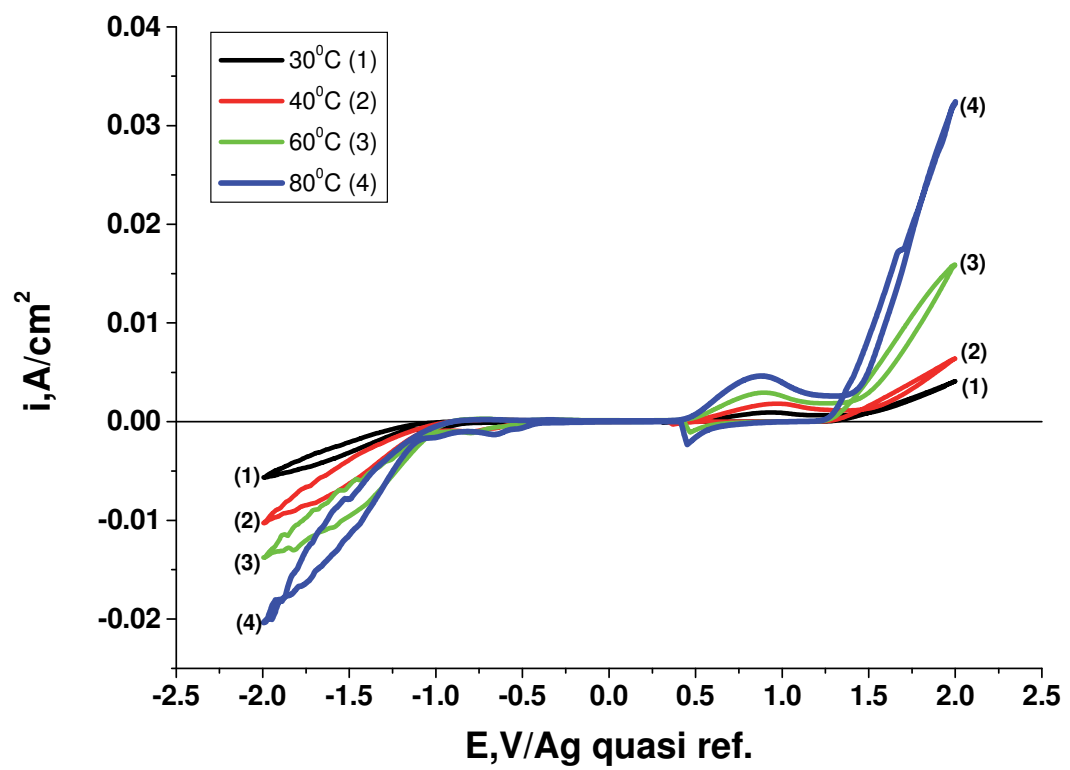

Fig. 5. Cyclic voltammograms for choline chloride-urea- $\mathrm{NiCl}_{2}$ systems containing $0.1 \mathrm{M} \mathrm{Ni}{ }^{2+}$ at various temperature values.

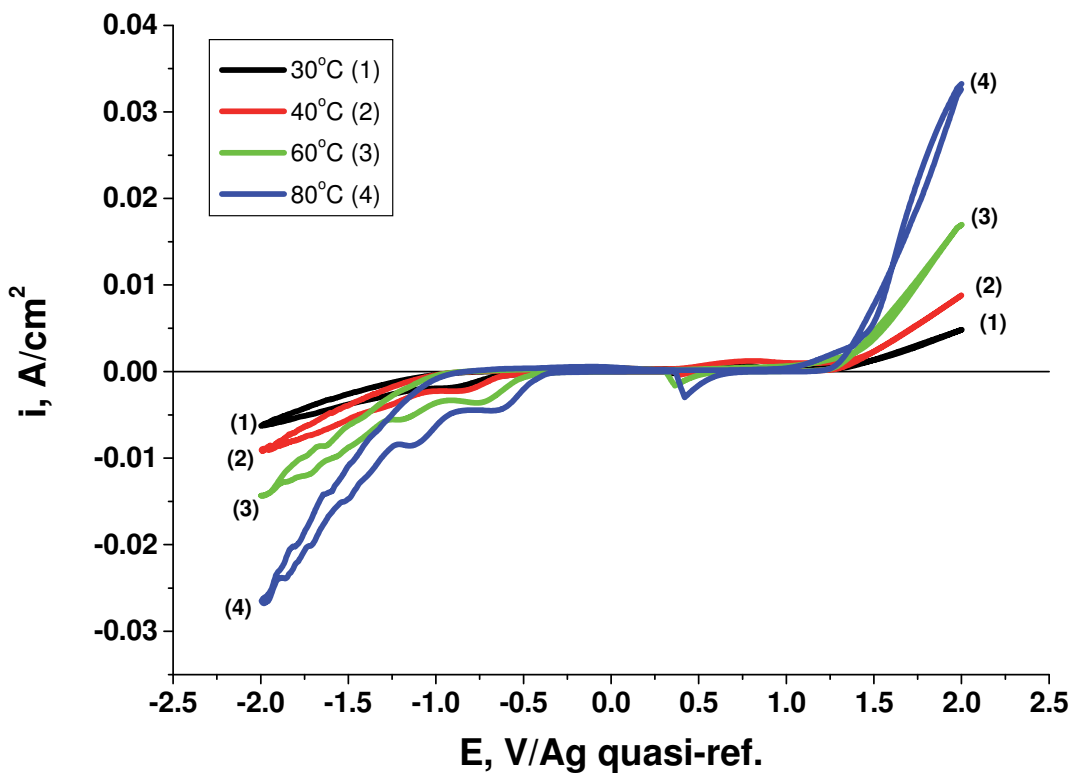

Fig. 6. Cyclic voltammograms for choline chloride-urea- $\mathrm{NiCl}_{2}$ systems containing $0.5 \mathrm{M} \mathrm{Ni}^{2+}$ at various temperature values. 


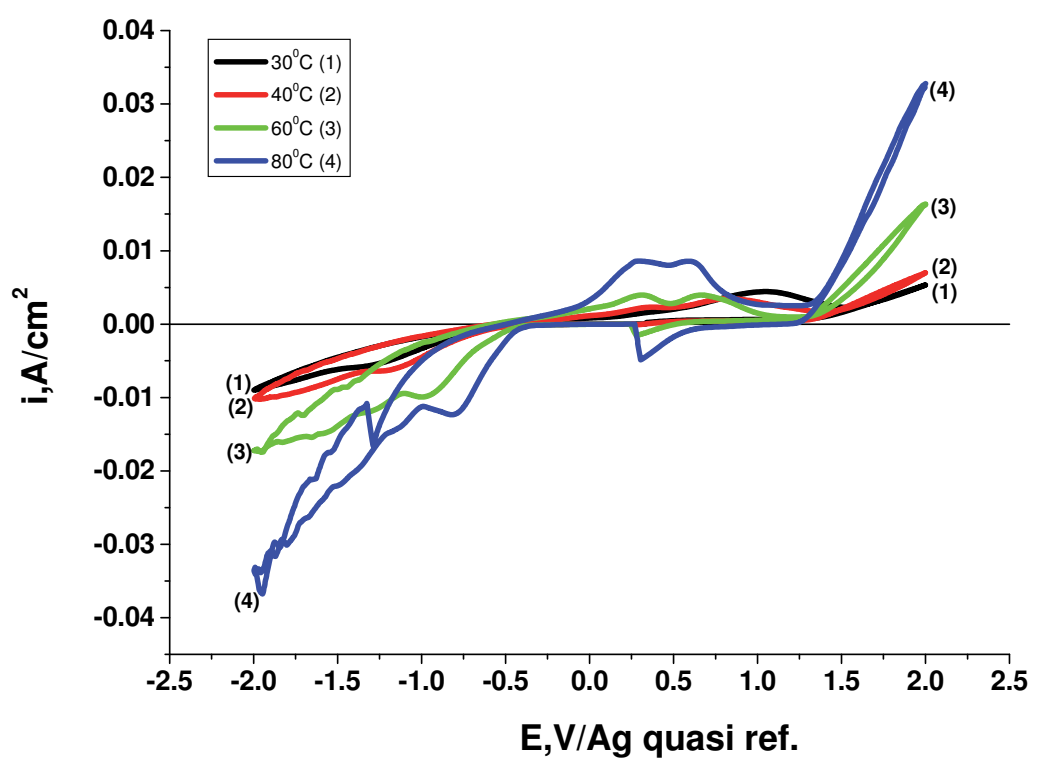

Fig. 7. Cyclic voltammograms for choline chloride-urea- $\mathrm{NiCl}_{2}$ systems containing $1 \mathrm{M} \mathrm{Ni}^{2+}$ at various temperature values.

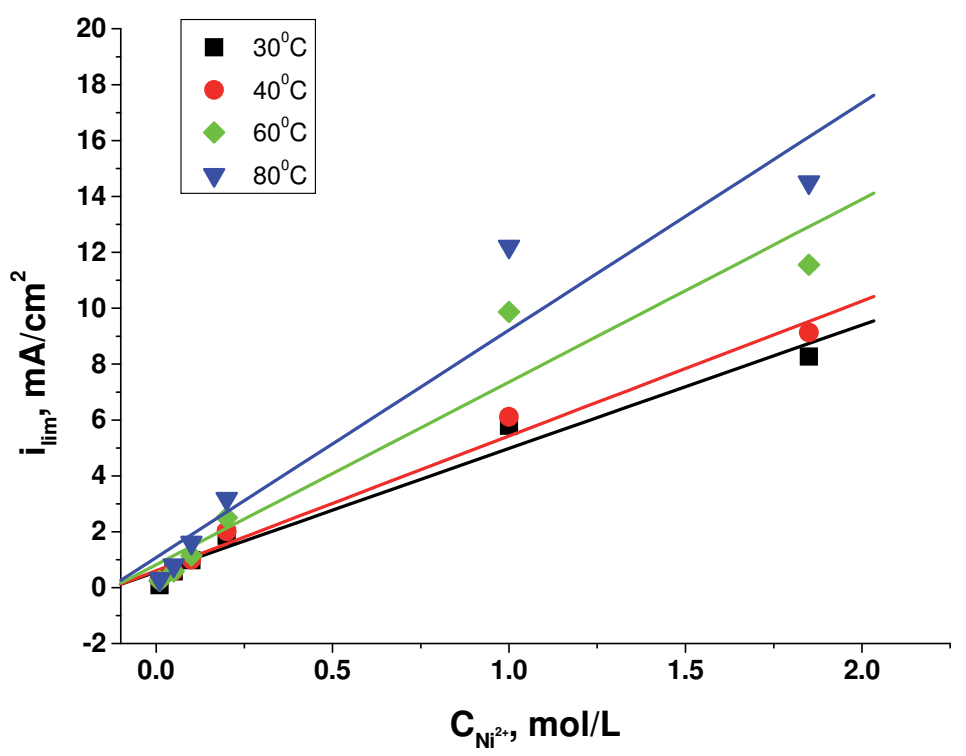

Fig. 8. Plots of cathodic limiting current vs. $\mathrm{Ni}^{2+}$ concentration for $\mathrm{IL}^{-\mathrm{NiCl}_{2}}$ systems at different temperatures. 
On the anodic scan the dissolution peak is observed at around $0.85-1.05 \mathrm{~V} / \mathrm{Ag}$ quasi-ref., and shifts to more negative values as the operating temperature increases.

If the dependence of the cathodic limiting current $i_{\text {lim }}$ against $\mathrm{Ni}^{2+}$ concentration $-\mathrm{C}_{\mathrm{Ni}(\mathrm{II})}$ is analysed one can find a linear relationship for the investigated temperature domain, as is also shown in Figure 8. The following empirical equation may be written:

$$
i_{\lim }=A+B \cdot c_{N i^{2+}}
$$

where A and B are y-intercept and slope of the lines from Figure 8, respectively, which are temperature dependent. A and B values against temperature are shown in Table 2.

\begin{tabular}{|c|c|c|}
\hline $\mathrm{T},{ }^{\circ} \mathrm{C}$ & $\mathbf{A}$ & $\mathbf{B}$ \\
\hline 30 & 0.56253 & 4.41926 \\
\hline 40 & 0.60644 & 4.82317 \\
\hline 60 & 0.81778 & 6.53998 \\
\hline 80 & 1.07909 & 8.1366 \\
\hline
\end{tabular}

Table 2. Values of A and B at different temperatures.

The dependencies of $A$ and $B$ against $1 / T$ as are shown in Figures 9 and 10 are linear, too, so that the equations (5) and (6) can be written, respectively:

$$
\begin{gathered}
\log A=a+b \bullet 1 / T \\
B=\alpha+\beta \bullet 1 / T
\end{gathered}
$$

Thus a mathematical correlation between the cathodic limiting current, metallic cation concentration in the ionic liquid and the temperature may be proposed, as follows:

$$
\begin{gathered}
\mathrm{i}_{\lim }=10(\mathrm{a}+\mathrm{b} / \mathrm{T})+(\alpha+\beta 1 / \mathrm{T}) \bullet \mathrm{c}_{\mathrm{Ni}^{2+}} \\
\mathrm{i}_{\lim }=10(1.78-622.7 / \mathrm{T})+(31.2-8186 / \mathrm{T}) \bullet \mathrm{c}_{\mathrm{Ni}^{2+}}
\end{gathered}
$$

Thus, relationship (8) allows the calculation of the cathodic limiting current as a function of $\mathrm{Ni}(\mathrm{II})$ concentration in the ionic medium at the applied temperature. This behaviour proves the diffusive character of the electrode process control.

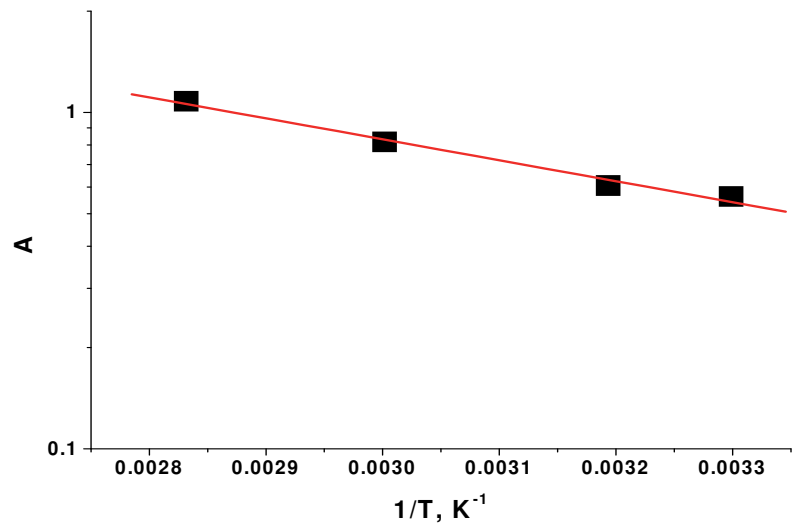

Fig. 9. Plot of $\log \mathrm{A}$ against 1/T. 


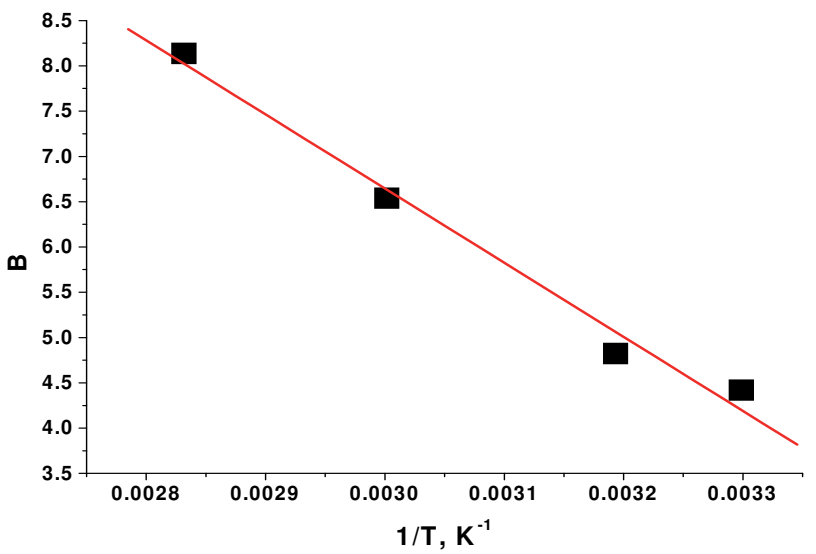

Fig. 10. Plot of B versus 1/T.

Figures 11 and 12 show examples of the recorded voltammograms at different applied working temperatures for the case of choline chloride-urea based ionic liquids where the cation source has been provided as sulfate. The reduction potential of $\mathrm{Ni}^{2+}$ cationic species is situated in the range of $-0.650 \div-0.730 \mathrm{~V} / \mathrm{Ag}$ quasi ref. and it is shifted with about $50-100$ $\mathrm{mV}$ towards more electropositive values as the temperature increased. For ionic liquids systems containing metallic cation species concentrations higher than $0.2 \mathrm{M}$ a second cathodic peak was evidenced at $-1.05 \div-1.1 \mathrm{~V} / \mathrm{Ag}$ quasi ref., for temperatures above $60^{\circ} \mathrm{C}$.

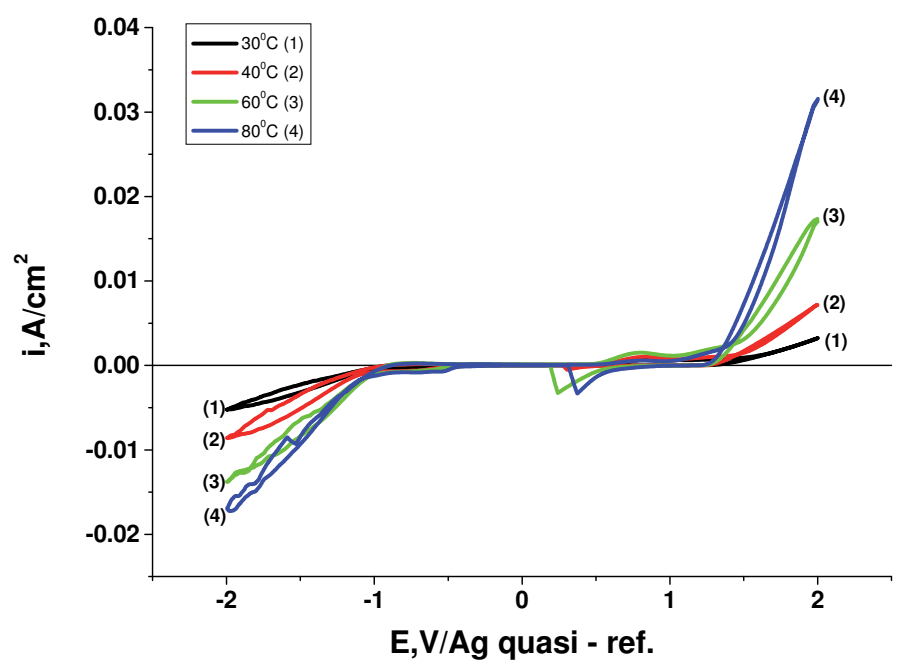

Fig. 11. Cyclic voltammograms for choline chloride-urea- $\mathrm{NiSO}_{4}$ systems containing $0.1 \mathrm{M}$ $\mathrm{Ni}^{2+}$ at various temperature values.

This behaviour may suggest a sequence of reduction processes for some possible nickel complex compounds in the presence of an ionic medium containing chloride anions and ammonium cations (from the eutectic composition acting as a solvent) (Ji \& Cooper, 1996; Zheng et al., 2005). 
The same linear dependence in agreement with equation (4), between the cathodic limiting current $\mathrm{i}_{\text {lim }}$ against $\mathrm{Ni}^{2+}$ concentration $-\mathrm{C}_{\mathrm{Ni} \text { (II) }}$ has been also found for $\mathrm{IL}^{2} \mathrm{NiSO}_{4}$ system for the investigated domain, as shown in Figure 13. Following the same processing procedure as in the previous system, a similar mathematical correlation between the cathodic limiting current, metallic cation concentration (introduced as sulfate) in the ionic liquid and the temperature was proposed:

$$
\mathrm{i}_{\lim }=10(92.9 / \mathrm{T}-0.9)+(35.1-10177.8 / \mathrm{T}) \bullet \mathrm{c}_{\mathrm{Ni}^{2+}}
$$

Based on the relationships (8) and (9) one can conclude that the reduction process of the metallic cations from chloride salts occurs with relatively higher rates as compared with the use of sulfates, materialized by higher values of the cathodic limiting currents.

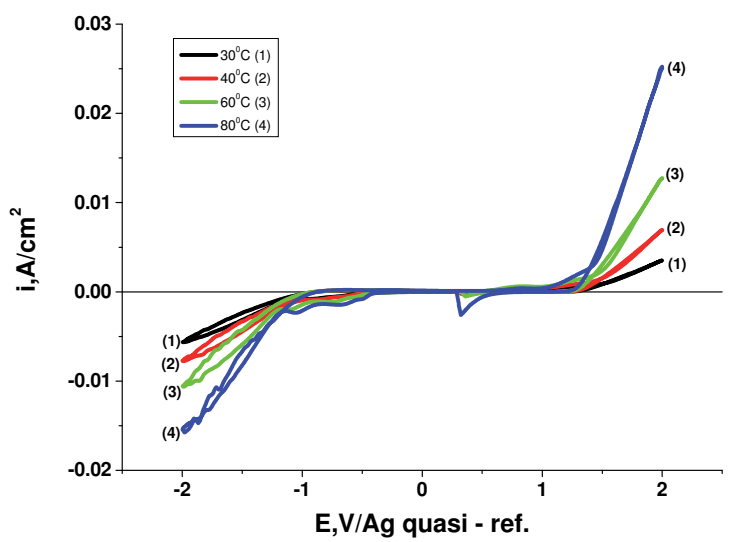

Fig. 12. Cyclic voltammograms for choline chloride-urea- $\mathrm{NiSO}_{4}$ systems containing $0.2 \mathrm{M}$ $\mathrm{Ni}^{2+}$ at various temperature values.

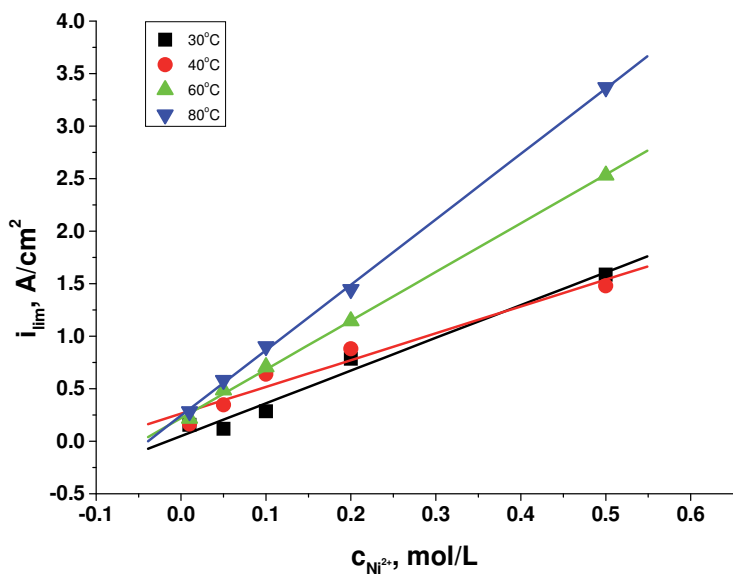

Fig. 13. Plots of cathodic limiting current $v s$. $\mathrm{Ni}^{2+}$ concentration for $\mathrm{IL}^{2} \mathrm{NiSO}_{4}$ systems at different temperatures. 
This fact has been experimentally confirmed. For example for an ionic medium based on $0.2 \mathrm{M} \mathrm{Ni}^{2+}$ in ChCl-urea eutectic mixture, a cathodic current of $0.881 \mathrm{~mA} / \mathrm{cm}^{2}$ has been determined when the salt has been added as sulfate as compared with a value of 2.012 $\mathrm{mA} / \mathrm{cm}^{2}$ in the case of metallic chloride utilization, for a working temperature of $40^{\circ} \mathrm{C}$. The diffusive character of the electrode process control evidenced by the linear dependence between the cathodic limiting current and cation concentration was found to be the same regardless the metallic salt anion and regardless the type of the eutectic mixture (Florea, 2010).

\subsection{Ni layers electrodeposition - technological aspects}

To evaluate the quality of the electrochemical coatings obtained from choline chloride based ionic liquids, constant current electrolyses were carried out under stationary conditions and in open air (the electrolyte has been in contact with atmospheric air and humidity). Different ionic liquids systems have been involved, as shown in Table 3. A two-electrode configuration has been employed, using various metallic substrates, respectively of $\mathrm{Cu}, \mathrm{Al}$ and $\mathrm{Mg}$ as metallic substrates, of $70 \times 35 \mathrm{~mm}$ sizes, with a constant geometrical area of 24.5 $\mathrm{cm}^{2}$. Table 4 briefly presents the surface preparation of the metallic electrode before electrodeposition, as well as the electrolysis conditions.

\begin{tabular}{|c|c|c|c|}
\hline No. & System type & $\begin{array}{l}\text { Solvent composition } \\
\text { (molar ratio) }\end{array}$ & $\begin{array}{l}\text { Metallic compound concentration } \\
\text { (Mole/L) }\end{array}$ \\
\hline 1 & IL-Ni-chloride & Choline chloride-urea 1:2 & $0.42-1.68 \mathrm{M} \mathrm{NiCl}_{2} \cdot 6 \mathrm{H}_{2} \mathrm{O}$ \\
\hline 2 & IL-Ni-sulfate & Choline chloride-urea 1:2 & $0.71 \mathrm{M} \mathrm{NiSO}_{4} .7 \mathrm{H}_{2} \mathrm{O}$ \\
\hline 3 & IL-Ni & \multicolumn{2}{|c|}{$\begin{array}{c}\text { Choline chloride-urea }-\mathrm{NiCl}_{2} .6 \mathrm{H}_{2} \mathrm{O} \\
\text { (molar ratio) }\end{array}$} \\
\hline
\end{tabular}

Table 3. Ionic liquids systems involved in Ni electrodeposition.

\begin{tabular}{|c|c|c|}
\hline $\begin{array}{c}\text { Metallic substrate } \\
\text { type }\end{array}$ & Surface preparation & Electrolysis conditions \\
\hline $\begin{array}{l}\text { Cu sheet, } 99.99 \% \text {, } \\
\text { 70x35 mm; }\end{array}$ & $\begin{array}{c}\text { I.Pickling in 1:1 } \mathrm{HNO}_{3}: \mathrm{H}_{2} \mathrm{O} \text { for } 10-20 \mathrm{~s} ; \\
\text { II. Rinsing; } \\
\text { III.Drying; }\end{array}$ & \multirow{3}{*}{$\begin{array}{c}\text { Duration: } 10-60 \text { min. } \\
\text { Temperature: } \\
30-80^{\circ} \mathrm{C} \\
\text { Current density: } \\
\text { 1-18 A/dm² } \\
\text { Stationary conditions } \\
\text { Anode: Graphite/Nickel }\end{array}$} \\
\hline $\begin{array}{l}\text { Al strip, } \\
99.5 \% \text { purity } \\
\text { (thermally } \\
\text { treated), } \\
70 \times 35 \mathrm{~mm} \text {; }\end{array}$ & $\begin{array}{c}\text { I. Alkaline degreasing in: } \\
5-10 \mathrm{~g} / \mathrm{L} \mathrm{NaOH}+30-40 \mathrm{~g} / \mathrm{L} \mathrm{Na} \mathrm{CO}_{3} .10 \\
\mathrm{H}_{2} \mathrm{O}+30-40 \mathrm{~g} / \mathrm{L} \mathrm{Na} \mathrm{PO}_{4} .10 \mathrm{H}_{2} \mathrm{O} \\
\text { at } 60-70 \mathrm{oC} \text {, for } 15-20 \mathrm{~min} ; \\
\text { II. Rinsing; } \\
\text { III.Drying }\end{array}$ & \\
\hline $\begin{array}{l}\text { Mg foil, } \\
99.5 \% \text { purity, } \\
50 \times 3 \mathrm{~mm}\end{array}$ & $\begin{array}{l}\text { I. Mechanical preparation with abrasive } \\
\text { paper of } 1000 \text { and 2000; } \\
\text { II. Pickling in 1:4 (volumic ratio) } \mathrm{HF}: \mathrm{H}_{2} \mathrm{O} \\
\text { for } 30-60 \mathrm{~s} ; \\
\text { III. Rinsing; } \\
\text { IV. Drying. }\end{array}$ & \\
\hline
\end{tabular}

Table 4. Surface preparation of the involved metallic substrates and Ni electrodeposition conditions from the ionic systems shown in Table 3. 
The obtained electrodeposits have been characterized with respect to appearance, adherence and layer thickness (deposition rate). In order to obtain information about the composition and the structure of the deposit, XRD investigations were performed, too. Morphological investigations have been performed involving AFM (Quesant Scope 350 equipment), SEM associated with EDX analysis (Zeiss EVO 50 equipment provided with Bruker-EDX probe) and optical microscopy involving OPTIKA B-253 equipment with a digital EverFocus Model EQ250 video color camera.

\subsubsection{Nickel electrodeposition from choline chloride based ionic liquids containing chlorides}

Generally, the electrodepositions have been characterized by a very good adherence on $\mathrm{Cu}$ metallic substrates. The use of working temperatures of $\mathrm{min} .60^{\circ} \mathrm{C}$ and relatively high current densities in the range of 3.5-8.5 A/ $\mathrm{dm}^{2}$ determined the formation of light grey, uniform deposits, relatively similar to the semi bright Ni coatings obtained in aqueous electrolytes.

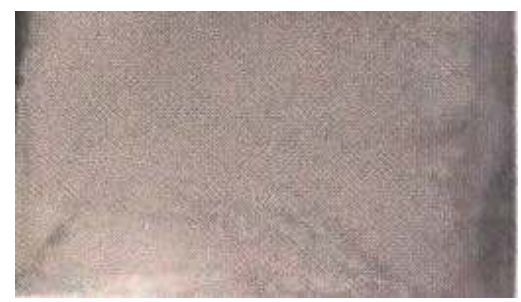

Fig. 14. Photograph of a Ni coating onto $\mathrm{Cu}$ substrate using IL-Ni-chloride system as electrolyte $\left(\mathrm{i}=.35 \mathrm{~A} / \mathrm{dm}^{2}, 70^{\circ} \mathrm{C}, 60 \mathrm{~min}\right.$.).

Figure 14 shows a photograph of a Ni deposit onto $\mathrm{Cu}$ substrate and Figure 15 presents two examples of the coating morphology from IL-Ni electrolyte against a $\mathrm{Ni}$ anode, through AFM images.
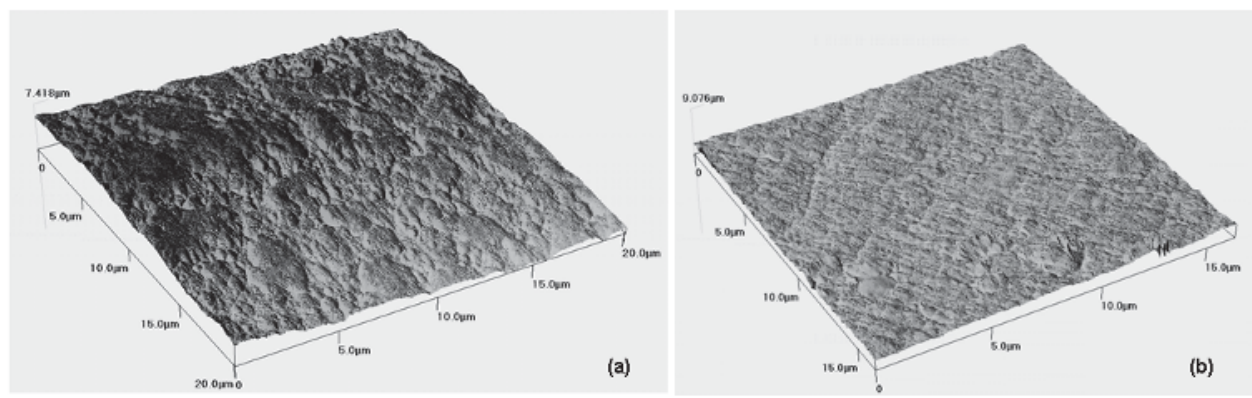

Fig. 15. AFM images of Ni electrodeposited on $\mathrm{Cu}$ substrate from IL-Ni-chloride system containing $0.5 \mathrm{M} \mathrm{NiCl}_{2}$ for various operating conditions: (a) $1 \mathrm{~A} / \mathrm{dm}^{2}, 50{ }^{\circ} \mathrm{C}, 30 \mathrm{~min}$. and (b) $0.65 \mathrm{~A} / \mathrm{dm}^{2}, 30^{\circ} \mathrm{C}, 30 \mathrm{~min}$. , against a Ni anode.

The presence of some cracks within the layer were noticed, less pronounced when a $\mathrm{Ni}$ anode has been involved, maybe due to the still present hydrogen discharge reaction that may be facilitated by the water content, of about $5-10 \%$ in the ionic liquid. Mechanical 
stresses that might be developed during deposition are not excluded, due to the relative high content of chlorides, which may also be responsible for cracks.

The use of soluble Ni anode facilitated an easier operation of IL-Ni electrolyte as compared with a graphite one, materialized by a better control of nickel content in the bath and by formation of a brighter coating layer.

According to XRD investigations and using the Scherrer's formula $(d=0,9 \lambda /(\beta \cos \theta)$, where $\lambda$ is $X$-ray wavelength, $\theta$ represents the diffraction angle and $\beta$ is the half width at half height for the diffraction peak in radians), average sizes of the crystallites have been of 9.2 $14.4 \mathrm{~nm}$, higher for increased applied current densities, maybe due to the temperature increase during electrodeposition. An amorphous phase is also observed, as it can be seen in Figure 16.

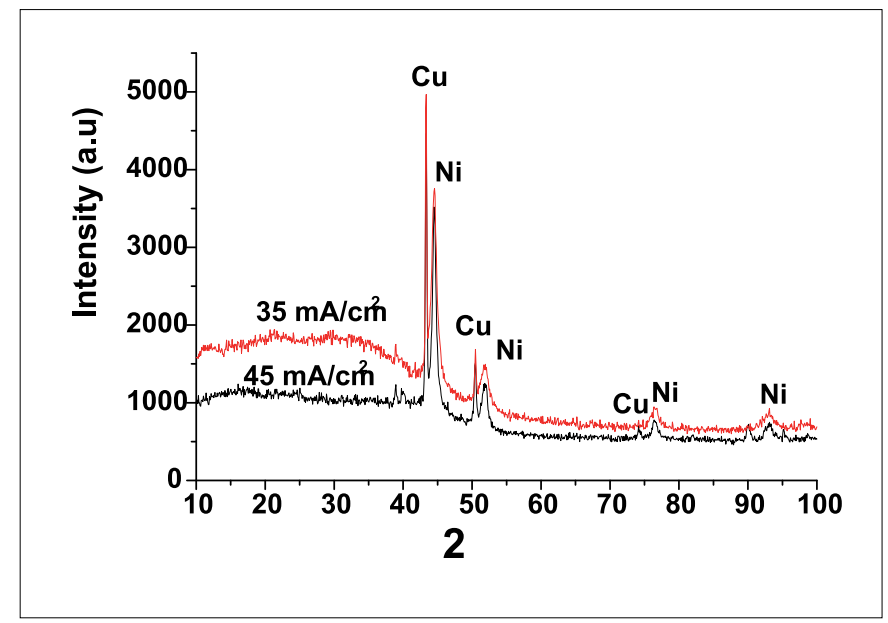

Fig. 16. X-ray diffractograms for electrodeposited Ni from an IL containing 1.84M $\mathrm{NiCl}_{2} \cdot 6 \mathrm{H}_{2} \mathrm{O}\left(70^{\circ} \mathrm{C}, 60 \mathrm{~min}\right.$.).

The deposition rate at various applied current densities was determined using gravimetric method. Thus, it has been founded that the ionic liquid electrolyte allows relatively low deposition rates, in the range of $0.1-0.4 \mu \mathrm{m} / \mathrm{min}$. for the investigated current densities domain, as compared to aqueous solutions which show typical values of $0.5-1 \mu \mathrm{m} / \mathrm{min}$.

When the IL-Ni system (as noted in Table3) has been involved, consisting of ChCl-urea$\mathrm{NiCl}_{2} \cdot 6 \mathrm{H}_{2} \mathrm{O}$ mixture in a 1:2:0.5 molar ratio, light grey, semi bright, uniform deposits have been formed, with an excellent adhesion onto $\mathrm{Cu}$ substrate. Cathodic efficiencies between $85-99 \%$ have been determined when the operation temperature was in the range of $60-70^{\circ} \mathrm{C}$, for electrolysis periods of 20-40 minutes.

This system was then used to electrodeposit Ni layers onto $\mathrm{Al}$ and $\mathrm{Mg}$ substrates. Adherent, mat black deposits onto $\mathrm{Al}$ have been obtained at current densities of about $1-1.1 \mathrm{~A} / \mathrm{dm}^{2}$ and relatively high temperatures of $80^{\circ} \mathrm{C}$ for deposition durations of minimum 30 minutes. Adherent, mat grey-black and slightly porous layers have been evidenced onto Mg substrate for the same operation conditions. Figures 17 and 18 present examples of optical micrographies of $\mathrm{Ni}$ deposits onto $\mathrm{Al}$, respectively onto $\mathrm{Mg}$ substrates from IL-Ni electrolyte, at $1 \mathrm{~A} / \mathrm{dm}^{2}, 80^{\circ} \mathrm{C}$, for 30 minutes. 

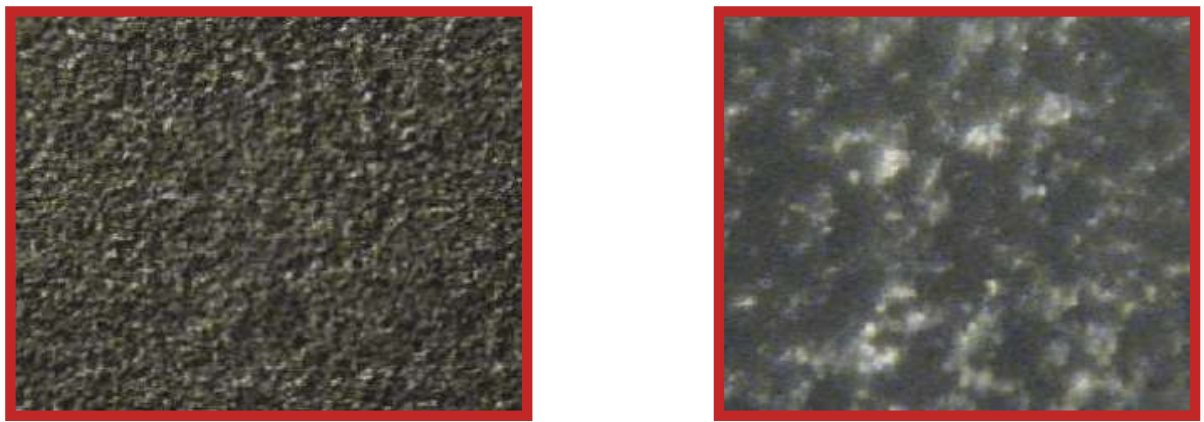

Fig. 17. Optical micrographies of Ni deposits onto Al substrate from IL-Ni system, $1 \mathrm{~A} / \mathrm{dm}^{2}$, $80^{\circ} \mathrm{C}, 30$ minutes. Left: magnification: X40; Right: magnification : X 400.
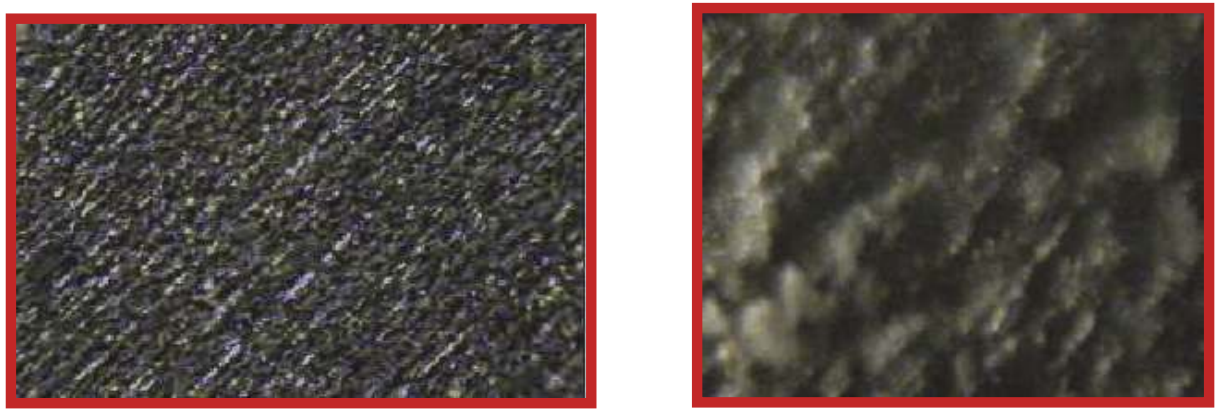

Fig. 18. Optical micrographies of $\mathrm{Ni}$ deposits onto $\mathrm{Mg}$ substrate from IL-Ni system, $1.1 \mathrm{~A} / \mathrm{dm}^{2}, 80^{\circ} \mathrm{C}, 30$ minutes. Left: magnification: X40; Right: magnification : X 400.

\subsubsection{Nickel electrodeposition from choline chloride based ionic liquids containing sulphates}

The Ni electrodeposition from choline chloride based ionic liquids containing the metallic cation as sulfate (see Table 3) was also investigated, onto the same previously mentioned metallic substrates, respectively $\mathrm{Cu}, \mathrm{Al}$ and $\mathrm{Mg}$ ones. The electrolysis was performed using a $\mathrm{Ni}$ anode for coating durations between 30-60 minutes.

Suitable coatings with a very good adherence were deposited onto $\mathrm{Cu}$ substrate. Temperatures of minimum $70^{\circ} \mathrm{C}$ and current densities of $1-1.5 \mathrm{~A} / \mathrm{dm}^{2}$ afford optimum coatings. The deposit entirely covers the metallic copper substrate, with a very good uniformity. Usually metallic grey layers are formed, with a micro/nano-crystalline structure.

When Ni electrodeposition using IL-Ni-sulfate system is applied onto Al substrate, uniform, dull, dark grey up to black layers are obtained for current densities between $10-15 \mathrm{~mA} / \mathrm{cm}^{2}$, at $80 \circ \mathrm{C}$. The coating is adherent to the substrate in the most of the cases.

However, if the specimen is bent at $90^{\circ}$, a partial detaching was noticed (see Figure 19) suggesting the presence of a thin oxide layer that hinders the direct contact between $\mathrm{Al}$ and Ni deposit. 

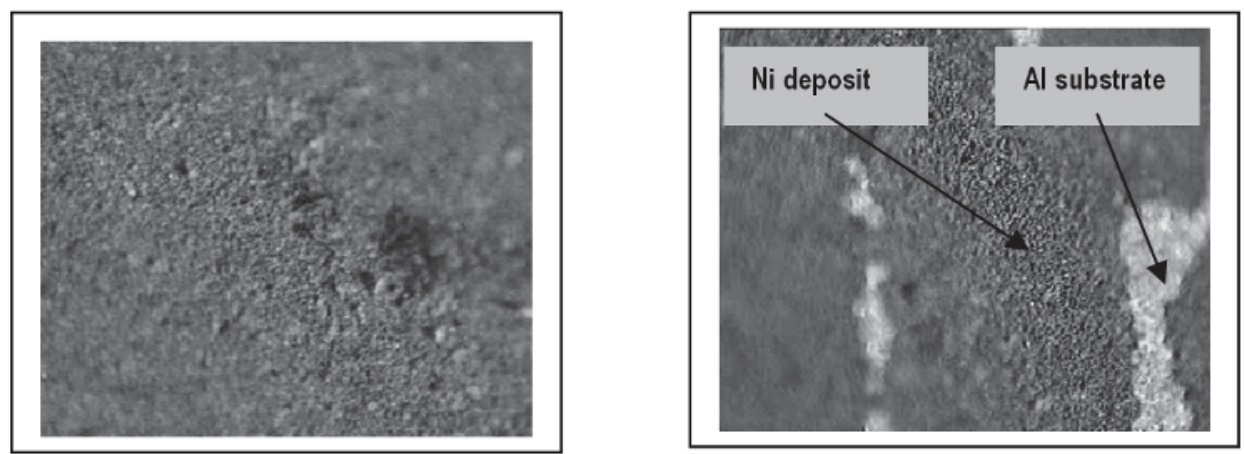

Fig. 19. Optical micrography of Ni electrodeposited onto Al substrate from IL-Ni-sulfate containing $0.71 \mathrm{M} \mathrm{NiSO} 41 \mathrm{~A} / \mathrm{dm}^{2}, 80^{\circ} \mathrm{C}, 30 \mathrm{~min}$. (left) and coating cracking after adherence test (right). Magnification : X 100.

Figure 20 presents am AFM image of the Ni deposit on Al from IL-Ni-sulfate system. The presence of spherical, cluster like formations can be clearly observed. A coating thickness of about $4 \mu \mathrm{m}$ and a roughness around of $430 \mathrm{~nm}$ have been estimated, probably due to the initial non-homogeneities of the $\mathrm{Al}$ metallic substrate.
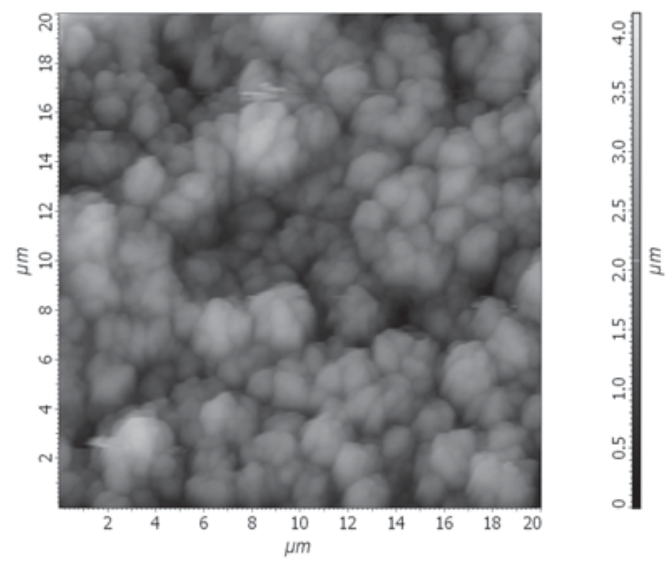

Fig. 20. AFM image of Ni electrodeposited onto Al from IL-Ni-sulfate system at 2.5 $\mathrm{mA} / \mathrm{cm}^{2}, 80^{\circ} \mathrm{C}, 60 \mathrm{~min}$.

$\mathrm{Ni}$ coatings were successfully electrodeposited directly onto $\mathrm{Mg}$ substrate. The formed layers in this case are dull grey, uniform on the entire surface, with a good adherence on the substrate and slightly porous (Florea et al., 2010) .

\subsubsection{Corrosion behaviour of Ni coatings obtained from choline chloride based ionic liquids}

In order to get some information on the corrosion protection performance of the electrodeposited Ni coatings from choline chloride based ionic liquids, several accelerated 
corrosion tests were performed: (i) continuous immersion in $0.5 \mathrm{M} \mathrm{NaCl}$ for 336 hours with intermediary visual examinations and recording of corrosion potential; (ii) potentiodynamic polarization curves in aerated $0.5 \mathrm{M} \mathrm{NaCl}$ against a $\mathrm{Ag} / \mathrm{AgCl}$ reference electrode and $\mathrm{Pt}$ mesh counterelectrode, with a sweep rate of $5 \mathrm{mV} / \mathrm{s}$ and (iii) impedance spectra at open circuit potential, in a frequency range between $10^{5} \mathrm{~Hz}-0.1 \mathrm{~Hz}$. in the same three electrodes cell. For both electrochemical investigations the geometrical surface of working electrode was $0.63585 \mathrm{~cm}^{2}$. Three $\mathrm{Cu}$ specimens of $35 \times 70 \mathrm{~mm}$ have been electrochemically coated with Ni deposits using IL-Ni system (see Table 3) of 10-15 $\mu \mathrm{m}$ and subjected to the corrosion tests. Figure 21 shows an example of the recorded impedance spectra for $\mathrm{Ni}$ deposit as Nyquist plot.

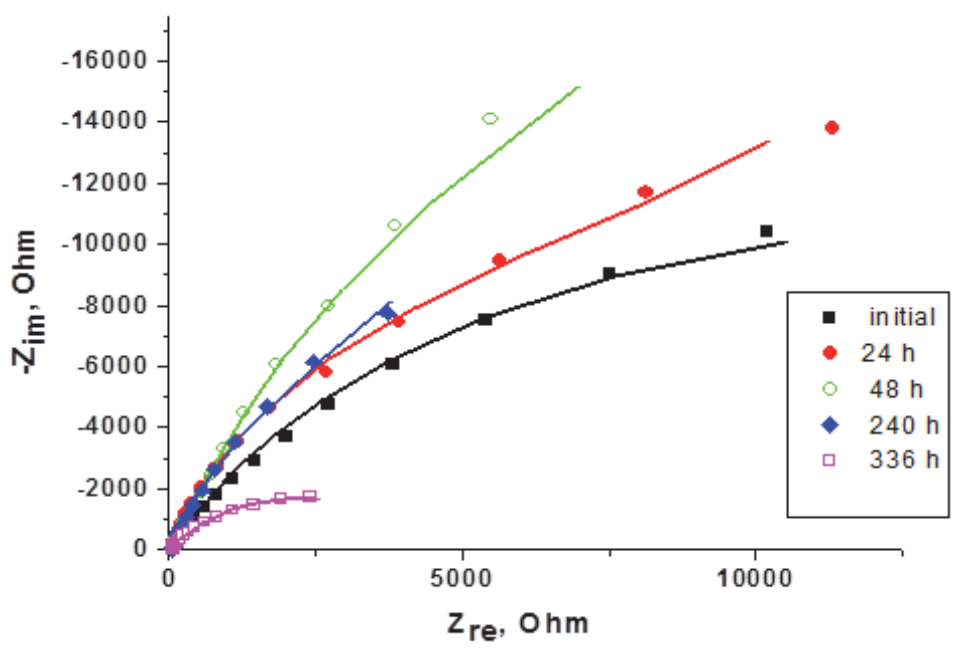

Fig. 21. Nyquist plot in $0.5 \mathrm{M} \mathrm{NaCl}$ at open circuit potential for Ni coating initially and after various periods of continuous immersion, representing both experimental and fitted (solid lines) points

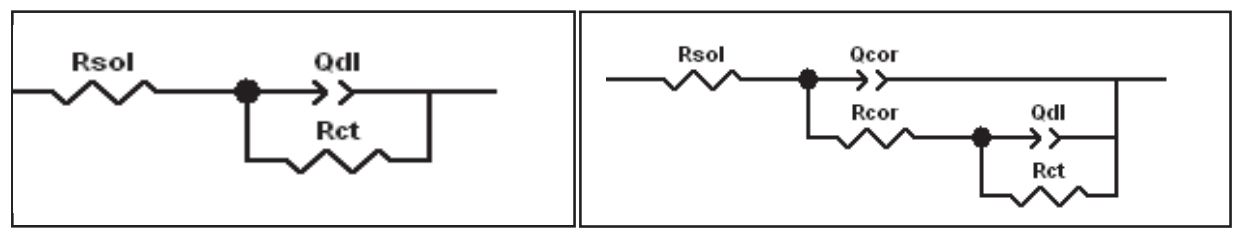

(a)

(b)

Fig. 22. The proposed equivalent circuits to fit the experimental data from Figure 21 
To fit experimental data, a simple equivalent circuit model has been used (as shown in Figure 22a), comprising the solution resistance $\left(\mathrm{R}_{\mathrm{Sol}}\right)$, in series with a combination between a constant phase element corresponding to the double layer capacitance (Qdl) in parallel with charge transfer resistance (Rct). After 96 hours of immersion, a second time constant can be noticed on Bode plots which may be associated with corrosion processes determined by the pitting initiation at the coating surface. In this case, a different circuit model has been used by addition of two more elements, $\mathrm{Q}$ cor and Rcor (see Figure 22b). This model considers that the passive film doesn't entirely cover the metallic surface. As it can be seen from Figure 21, at the initial moment of immersion the charge transfer resistance is about $30 \mathrm{k} \Omega$ comparable to those obtained in $\mathrm{Ni}$ aqueous electrolytes. As the immersion period increases, the Rct increases towards $70 \mathrm{k} \Omega$ after 48 hours, due to the formation of a thin passive film on the metallic surface, which may enhance protective characteristics. This is a common occurence in the case of $\mathrm{Ni}$ immersion in aerated solutions. On visual examination of the metallic specimens, no significant surface modifications were found and no pits were observed.

\section{Conclusions}

The performed investigations showed the possibility of ILs preparation with quite large concentrations of $\mathrm{Ni}$ (II) compounds $\left(0-1.68 \mathrm{M} \mathrm{NiCl}_{2} \cdot 6 \mathrm{H}_{2} \mathrm{O}\right.$, respectively $\left.0-1 \mathrm{M} \mathrm{NiSO} \cdot 7 \mathrm{H}_{2} \mathrm{O}\right)$ using deep eutectic solvents involving choline chloride. The formed low temperature melts are characterized by a good stability in time and are liquid at $25-30^{\circ} \mathrm{C}$.

The cyclic voltamogramms evidenced the Ni (II) reduction at about $-1.05 \mathrm{~V} / \mathrm{Ag}$ crsi-ref. for low working temperatures $\left(30^{\circ} \mathrm{C}\right)$ which shifts towards more positive values with temperature increase, towards $-0.75 \div-0.88 \mathrm{~V} / \mathrm{Ag}$ cvasi-ref at $80^{\circ} \mathrm{C}$. Usually the cathodic limiting current increases with temperature. The anion nature does not significantly influence the cathodic process.

The obtained $\mathrm{Ni}$ deposits are adherent and uniform onto $\mathrm{Cu}$ substrate and the morphology evidenced the presence of some cracks that further may influence the corrosion behaviour. According to XRD investigations, average sizes of the crystallites have been of $9.2-14.4 \mathrm{~nm}$, higher for increased applied current densities, maybe due to the temperature increase during electrodeposition. Also an amorphous phase has been evidenced. The direct deposition of nickel on magnesium and aluminum was noticed from ILs containing either $\mathrm{NiCl}_{2}$ or $\mathrm{NiSO}_{4}$ as a source of metallic cations. Operating temperatures in the range of $60-$ $80^{\circ} \mathrm{C}$ and applied current densities in the range of $40-150 \mathrm{~mA} / \mathrm{cm}^{2}$ are recommendable, to allow deposition rates of $0.1-0.4 \mu \mathrm{m} / \mathrm{min}$.

$\mathrm{Ni}$ alloys coatings formed in ILs showed a moderate corrosion protection, materialized in polarization resistances of $30-40 \mathrm{k} \Omega$, probably due to the cracked morphology. However, after 240 hours of continuous immersion in chloride containing aggresive aqueous medium the exposed specimens did not exhibited any major surface modification and no pits have been evidenced.

Further investigations will be performed, for a better understanding of metal deposition mechanism associated with obtained morphology as an important factor to influence the final performance and to establish industrially compliant technological processes. 


\section{Acknowledgment}

Part of this work was supported by the Romanian Ministry of Education and Research, PNCDI II Program, under Research Contract No.31066/1-2007.

\section{References}

Abbott, A.P.; Capper, G.; Davies, D.L.; Munro, H.L.; Rasheed, R.K. \& Tambyrajah, V. (2001), Preparation of novel, moisture stable, Lewis-acidic ionic liquids containing quaternary ammonium salts with functional side chains, Chem .Commun., No.19, 2001, pp. 2010-2011, ISSN 1359-7345

Abbott, A.P.; Capper, G.; Davies, D.L.; Rasheed, R.K. \& Tambyrajah,V. (2003), Novel solvent properties of choline chloride/urea mixtures, Chem. Commun., No.1, 2003, pp. 70-71, ISSN 1359-7345

Abbott, P.; Capper, G.; Davies, D.L.; Munro, H.; Rasheed, R.K. \& Tambyrajah, V. (2003). Electrochemical Studies of Ambient Temperature Ionic Liquids Based on Choline Chloride, In: Ionic liquids as green solvents: progress and prospects, Rogers, R.D. \& Seddom, K.R. (Ed)., pp. 439-452, An American Chemical Society Publication, ISBN: 9780841238565. Washington, DC

Abbott, A.P.; Capper, G.; Davies, D.L. \& Rasheed, R.K. (2004), Ionic liquids based upon metal halide/substituted quaternary ammonium salt mixtures, Inorg. Chem., Vol.43, No.11, May 2004, pp. 3447-3452, ISSN 0020-1669

Abbott, A.P.; Davies, D.L.; Capper, G.; Rasheed, R.K. \& Tambyrajah, V, USA Patent 2004/0097755

Abbott, A.P.; Boothby, D.; Capper, G.; Davies, D.L. \& Rasheed, R.K. (2004), Deep eutectic solvents formed between choline chloride and carboxylic acids: versatile alternatives to ionic liquids, J. Am. Chem. Soc., Vol.126, No.29, July 2004, pp. 91429147, ISSN 0002-7863

Abbott, A.P.; Capper, G.; Davies, D.L. \& Rasheed, R.K. (2004), Ionic liquid analogues formed from hydrated metal salts, Chem. Eur. J., Vol.10, No.15, August 2004, pp. 37693774, ISSN 1521-3765

Abbott, A.P.; Capper, G.; Davies, D.L.; Rasheed, R.K.; Archer, J. \& John, C. (2004), Electrodeposition of chromium black from ionic liquids, Trans. Inst. Met. Finish., Vol.82, No.1-2, 2004, pp. 14-17, ISSN 0020-2967

Abbott, A.; Davies, D.L.; Capper, G.; Rasheed, R.K. \& Tambyrajah, V., Ionic liquids and their use, Patent SUA nr.US 2004/0054231

Abbott, A.P.; Capper, G.; Davies, D.L.; Rasheed, R.K. \& Shikotra, P. (2005), Selective extraction of metals from mixed oxides matrixes using choline - based ionic liquids, Inorg. Chem., Vol.44, No.19, September 2005, pp. 6497-6499, ISSN 00201669

Abbott, A.P.; Capper, G.; McKenzie, K.J. \& Ryder, K.S. (2006), Voltammetric and impedance studies of the electropolishing of type 316 stainless steel in a choline chloride based ionic liquid, Electrochim. Acta, Vol.51, No. 21, June 2006, pp. 4420-4425, ISSN 00134686 
Abbott, A.P. \& McKenzie, K.J. (2006), Application of ionic liquids to the electrodeposition of metals, Phys. Chem. Chem. Phys., Vol.8, No.37, 2006, pp. 4265-4279, ISSN 14639076

Abbott, A.P.; Capper, G.; McKenzie, K.J. \& Ryder, K.S. (2007), Electrodeposition of zinc-tin alloys from deep eutectic solvents based on choline chloride, J. Electroanal. Chem., Vol.599, No.2, January 2007, pp. 288-294, ISSN 00220728

Abbott, A.P.; Barron, J.C.; Ryder, K.S. \& Wilson, D. (2007), Eutectic-Based Ionic Liquids with Metal-Containing Anions and Cations, Chem. Eur. J., Vol.13, No.22, July 2007, pp. 6495 - 6501, ISSN 1521-3765

Abbott, A.P.; Nandhra, S.; Postlethwaite, S.; Smith, E.L. \& Ryder, K. (2007), Electroless deposition of metallic silver from a choline chloride-based ionic liquid: a study using acoustic impedance spectroscopy, SEM and atomic force microscopy, Phys.Chem.Chem.Phys., Vol. 9, No.28, 2007, pp. 3735-3743, ISSN 14639076

Abbott, A.P.; Griffith, J.; Nandhra, S.; Connor, C.O.; Postlethwaite, S.; Ryder, K.S. \& Smith, E.L. (2008), Sustained electroless deposition of metallic silver from a choline chloride-based ionic liquid, Surf. Coat. Technol., Vol. 202, No.10, February 2008, pp. 2033-2039, ISSN 0257-8972

Abbott, A.P.; Ttaib, K.El; Ryder, K.S. \& Smith, E.L. (2008), Electrodeposition of nickel using eutectic based ionic liquids, Trans.Inst. Met. Finish., Vol.86, July 2008, pp. 234-240, ISSN 0020-2967

Abbott, P.; Barron, J. C. \& Ryder, K. S. (2009), Electrolytic deposition of Zn coatings from ionic liquids based on choline chloride, Trans.Inst.Met. Finish., Vol. 87 , No.4, July 2009, pp. 201-207, ISSN 0020-2967

Abbott, A.P.; Ttaib, K.El.; Frisch, G.; McKenzie, K. J. \& Ryder, K.S. (2009), Electrodeposition of copper composites from deep eutectic solvents based on choline chloride, Phys. Chem. Chem. Phys., Vol.11, No. 21, pp. 4269-4277, ISSN 14639076

Abbott, A.P.; Barron, J.C.; Frisch, G.; Ryder, K. S. \& Silva, A. F. (2010), The Effect of Additives on Zinc Electrodeposition from Deep Eutectic Solvents, Electrochim. Acta, doi:10.1016/j.electacta.2011.02.095 ISSN 0013-4686

Anicai, L; Cojocaru, A.; Florea, A. \& Visan, T. (2008), Electrochemical investigation of silver/silver ion couple reversibility in choline chloride-urea based ionic liquid, Studia Univ.Babes-Bolyai, Chemia, Vol.53, No.1, 2008, pp. 119-135, ISSN 12247154

Benaben, P. \& Sottil, B. (2006), Hard Chromium deposition using ionic liquids as a potential substitute to hexavalent chromium plating: First results in European IONMET programme 57-th Annual Meeting of ISE, Edinburgh, 2006, Abstracts, S5-O-3.

Chromium Electroplating: Ion Age Dawns,- Sustainble Technologies Initiative Program, 2004, www.oakdenehollins.co.uk/sti.html

Cojocaru, A.; Costovici, S.; Anicai, L.; Visan, T.; Cojocaru, P.; Magagnin, L. \& Cavallotti, P.L. (2009), Tin-Nickel alloy deposition from choline chloride-urea ionic liquids 
(Deposizione di una lega Nichel-Stagno da soluzioni ioniche a base di cloruro di colina-urea), Galvanotecnica e nuove finiture, No. 3, 2009, pp. 140-146

Cojocaru, A.; Costovici, S.; Anicai, L. \& Visan, T. (2009), Studies of cathodic processes during NiSn alloy deposition using choline chloride based ionic liquids, Metalurgia International, Vol.14, No.11, pp. 38-46, ISSN 1582-2214

Datta, M. \& Landolt, D. (2000), Fundamental aspects and applications of electrochemical microfabrication, Electrochim. Acta, Vol.45, No.15-16, May 2000, pp. 2535-2558, ISSN 0013-4686

Endres, F. (2002), Ionic Liquids: Solvents for the Electrodeposition of Metals and Semiconductors, Chem. Phys. Chem., Vol.3, February 2002, pp.144-154, ISSN 14397641

Endres, F.; Abbott, A. P. \& MacFarlane D.R. (2008), Electrodeposition from Ionic Liquids, WileyVCH Verlag, GmbH \& CO,KgaA, ISBN .978-3-527-31565-9, Weinheim

Florea, A.; Petica, A.; Anicai, L. \& Visan, T. (2010), Preliminary Studies Of Silver Coatings Formation From Choline Chloride Based Ionic Liquids, UPB Sci.Bull, Series B, Vol.72, No. 2, 2010, pp. 115-126, ISSN 1454-2331

Florea, A.; Anicai, L.; Costovici, S.; Golgovici, F \& Visan, T. (2010), Ni and Ni Alloys Coatings Electrodeposited from Choline Chloride Based Ionic Liquids Electrochemical Synthesis and Characterization, Surface and Interface Analysis, Vol.42, No.6-7, June - July 2010, pp. 1271-1275, ISSN 1096-9918

Florea, A. (2010), Metals and conducting polymers electrochemical coatings with controlled properties using ionic liquids media, Ph.D. Thesis, POLITEHNICA University, July 2010

Gurunathan, K.; Vadivel Murugan, A.; Marimuthu, R.; Mulik, U.P. \& Amalncrkar, D.P. (1999), Electrochemically synthesised conducting polymeric materials for applications towards technology in electronics, optoelectronics and energy storage devices, Materials Chemistry and Physics, Vol.61, No.3, November 1999, pp. 173-191, ISSN 0254-0584

Ji, J. \& Cooper, W.C. (1996), Nickel speciation in aqueous chloride solutions, Electrochim. Acta, Vol.41, No.9, June 1996, pp. 1549-1560, ISSN 00134686

Mukhopadhyay, I.; Aravinda, C.L.; Borissov, D. \& Freyland, W. (2005), Electrodeposition of $\mathrm{Ti}$ from $\mathrm{TiCl}_{4}$ in the ionic liquid l-methyl-3-butyl-imidazolium bis (trifluoro methyl sulfone) imide at room temperature: study on phase formation by in situ electrochemical scanning tunneling microscopy, Electrochim. Acta, Vol.50, No.6, January 2005, pp.1275-1281, ISSN 0013-4686

Wasserscheid, P. \& Welton, T. (2007), Ionic Liquids in Synthesis, Weinheim: Wiley-VCH Verlag, ISBN: 9783527312399

Whitehead, A.H.; Pölzler, M. \& Gollas, B. (2010), Zinc electrodeposition from a Deep Eutectic System Containing Choline Chloride and Ethylene Glycol, J. Electrochem. Soc., Vol. 157, No.6, pp. D328-D334, ISSN 0013-4651 
Zheng, G.; Zheng, L. \& Cao, H. (2005), Formation of black nickel in leaching solution containing ammonia and chloride, Trans. Nonferrous Met. Soc. China, Vol.15, No.1, February 2005, pp. 165-170, ISSN 1003-6326 


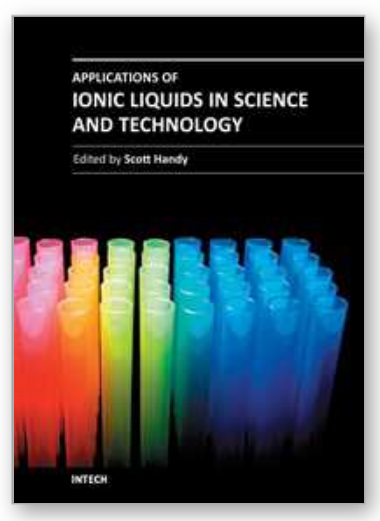

\author{
Applications of lonic Liquids in Science and Technology \\ Edited by Prof. Scott Handy
}

ISBN 978-953-307-605-8

Hard cover, 516 pages

Publisher InTech

Published online 22, September, 2011

Published in print edition September, 2011

This volume, of a two volume set on ionic liquids, focuses on the applications of ionic liquids in a growing range of areas. Throughout the 1990s, it seemed that most of the attention in the area of ionic liquids applications was directed toward their use as solvents for organic and transition-metal-catalyzed reactions. Certainly, this interest continues on to the present date, but the most innovative uses of ionic liquids span a much more diverse field than just synthesis. Some of the main topics of coverage include the application of RTILs in various electronic applications (batteries, capacitors, and light-emitting materials), polymers (synthesis and functionalization), nanomaterials (synthesis and stabilization), and separations. More unusual applications can be noted in the fields of biomass utilization, spectroscopy, optics, lubricants, fuels, and refrigerants. It is hoped that the diversity of this volume will serve as an inspiration for even further advances in the use of RTILs.

\title{
How to reference
}

In order to correctly reference this scholarly work, feel free to copy and paste the following:

Liana Anicai, Andreea Florea and Teodor Visan (2011). Studies Regarding the Nickel Electrodeposition from Choline Chloride Based Ionic Liquids, Applications of Ionic Liquids in Science and Technology, Prof. Scott Handy (Ed.), ISBN: 978-953-307-605-8, InTech, Available from:

http://www.intechopen.com/books/applications-of-ionic-liquids-in-science-and-technology/studies-regardingthe-nickel-electrodeposition-from-choline-chloride-based-ionic-liquids

\section{INTECH}

open science | open minds

\author{
InTech Europe \\ University Campus STeP Ri \\ Slavka Krautzeka 83/A \\ 51000 Rijeka, Croatia \\ Phone: +385 (51) 770447 \\ Fax: +385 (51) 686166 \\ www.intechopen.com
}

\author{
InTech China \\ Unit 405, Office Block, Hotel Equatorial Shanghai \\ No.65, Yan An Road (West), Shanghai, 200040, China \\ 中国上海市延安西路65号上海国际贵都大饭店办公楼 405 单元 \\ Phone: +86-21-62489820 \\ Fax: +86-21-62489821
}


(C) 2011 The Author(s). Licensee IntechOpen. This chapter is distributed under the terms of the Creative Commons Attribution-NonCommercialShareAlike-3.0 License, which permits use, distribution and reproduction for non-commercial purposes, provided the original is properly cited and derivative works building on this content are distributed under the same license. 